\title{
Oncological applications of positron emission tomography with fluorine-18 fluorodeoxyglucose
}

\author{
P. Rigo', P. Paulus ${ }^{1}$, B.J. Kaschten², R. Hustinx¹, T. Bury ${ }^{3}$, G. Jerusalem ${ }^{4}$, T. Benoit ${ }^{1}$, J. Foidart-Willems ${ }^{1}$ \\ 1 Division of Nuclear Medicine, University Hospital, Sart Tilman, Liege, Belgium \\ ${ }^{2}$ Cyclotron Research Centre, University of Liege and Division of Neurosurgery, University Hospital, Sart Tilman, Liege, Belgium \\ 3 Division of Pneumology, University Hospital, Sart Tilman, Liege, Belgium \\ ${ }_{4}^{4}$ Division of Onco-Hematology, University Hospital, Sart Tilman, Liege, Belgium
}

\begin{abstract}
Positron emission tomography (PET) is now primarily used in oncological indication owing to the successful application of fluorine-18 fluorodeoxyglucose (FDG) in an increasing number of clinical indications at different stages of diagnosis, and for staging and followup. This review first considers the biological characteristics of FDG and then discusses methodological considerations regarding its use. Clinical indications are considered, and the results achieved in respect of various organs and tumour types are reviewed in depth. The review concludes with a brief consideration of the ways in which clinical PET might be improved.
\end{abstract}

Key words: Positron emission tomography -- Fluorine-18 fluorodeoxyglucose - Oncology

Eur J Nucl Med (1996) 23:1641-1674

\section{Introduction}

Positron emission tomography (PET) is an imaging technology that delivers high-resolution images using biologically active compounds, substrates, ligands or drugs labelled with positron emitters [1]. These radiolabelled agents are primarily administered intravenously, distributed according to blood flow and utilized or processed in a manner virtually identical to their non-radioactive counterparts. They produce images and quantitative indexes of blood flow, glucose metabolism, amino acid transport, protein metabolism, neuroreceptor status, oxygen consumption or even cell division, etc. Since only tracer level amounts of material are administered, no pharmacological effect occurs and there is no perturbation of the targeted biochemical process [2-4]. Diagnosticians have traditionally been trained to analyse information provided by structural or anatomically based techniques. Biochemical processes are, however, altered in virtually all disease states and these alterations usual-

Correspondence to: P. Rigo, Nuclear Medicine, C.H.U. Sart Ti1man, B.35, B-4000 Liege 1, Belgium. ly precede gross anatomical changes. With the advent of molecular biology-based medicine, a transition must be made to incorporate information based on biochemical perturbations into diagnostic information, without waiting for structural changes. PET is one of the few clinical imaging techniques that provides such information. PET is also a very useful adjunct to anatomical imaging techniques, providing unique information and an additional dimension to the characterization of disease [5].

While applications initially focussed on the brain and the heart, PET is now primarily used in oncological indications. This development has resulted from the successful application of fluorine- 18 fluorodeoxyglucose (FDG) to a growing number of clinical indications at varying stages of diagnosis, staging and therapy follow-up of patients with cancer of many types and origins [6-8].

FDG uptake in cancer tissue is well documented in the literature and is based upon the increased glycolysis that is associated with malignancy as compared with most normal tissues $[9,10]$. The availability of a radioactive glucose analogue and of PET has allowed the study of glucose uptake in vivo. Initial work focussed on primary brain tumours as brain PET scanners were most commonly available. Di Chiro [11] first demonstrated that FDG PET was able to discriminate brain tumour recurrences from post-therapy changes. PET also provides a method to assess tumour grade and to evaluate patients' prognosis. With the advance of the whole-body imaging unit, the FDG technique has blossomed.

It is therefore appropriate to review the advantages and limitations of FDG as a tumour-seeking agent, its present and potential clinical role, the requirement for clinical improvement and widespread application of PET, and certain research perspectives.

\section{Biological characteristics of 18-FDG}

Use of FDG for in vivo cancer imaging is based on the observation of enhanced glycolysis in tumour cells. A high rate of "aerobic glycolysis" (degradation of glucose to lactic acid in the presence of oxygen) in several types 
of cancer cells was first described by Warburg $[12,13]$. This phenomenon has been linked to both an increase in the amount of glucose membrane transporters [14] and an increase in the activity of the principal enzymes controlling the glycolytic pathways.

Uptake of glucose and FDG into malignant cells is facilitated by an increased expression of the glucose transporter molecules at the tumour cell surface. Five transporters (GLUT1-GLUT5) are currently known and distributed in variable quantities among different tissues. GLUT1 and GLUT3 are the most frequent. GLUT4 depends on insulin for activation. Several papers suggest that activation of the gene coding for synthesis of the glucose transporter GLUT1 is a major early marker of cellular malignant transformation [15-20].

GLUT1 messenger RNA indeed increases 3-4 days before morphological transformation and this increase is not correlated with the cell proliferation rate [21-23]. Transfection to rat fibroblast of activated ras or $s r c$ oncogenes results in an elevation of the cytosolic concentration of mRNA responsible for the synthesis of glucose transporter [24]. In addition, an increased concentration of the mRNA has been linked to the increase in the number of glucose transporters in the malignant cell. In man, overexpression of GLUT1 and GLUT3 has been observed in several tumour types, including cerebral tumours, hepatocellular carcinoma and pancreatic tumours [25-28]. Furthermore, an increase in the activity of several enzymes controlling the glycolytic pathway has been demonstrated (hexokinase, phosphofructokinase, pyruvate dehydrogenase) [29]. For instance, several isoenzymes of hexokinase have been observed in the Novikoff ascites tumour [30].

FDG following intracellular transport is a substrate for hexokinase, the first enzyme of glycolysis. It is phosphorylated to FDG-6-phosphate. However, the second enzyme, glucose-6-phosphate isomerase, which transforms glucose-6-phosphate into fructose-6-phosphate, does not react with FDG-6-phosphate. Further, as the concentration of glucose-6-phosphatase is very low (except in the hepatocyte), the reverse transformation is not possible and FDG-6-phosphate remains trapped. Accessory metabolic pathways to gluconate and glucuronate are very slow and can be considered negligible within the time frame of the ${ }^{18} \mathrm{~F}$ half-life. The cellular concentration in ${ }^{18} \mathrm{~F}$ is therefore closely representative of the accumulated FDG-6-phosphate and of the glycolytic activity of exogenous glucose $[31,32]$.

Numerous studies have attempted to relate cellular FDG uptake to the biological properties of the tumour such as the histological grade, the proliferative activity, the doubling time and the number of viable tumour cells. A positive correlation between FDG uptake and the tumour grade has been reported in several tumour types including cerebral gliomas [33], liver tumours [34], nonHodgkin's lymphomas [35, 36] and some musculoskeletal tumour types [37, 38]. The relationship between tumour grade and uptake is, however, less marked in pul- monary tumours [7]. In hepatocellular carcinoma, the growth rate and the activity of glycolytic enzymes are related [39]. In head and neck tumours, the proliferative activity studied by DNA flow cytometry is related to FDG uptake while FDG does not reflect the tumour type. Further different cells of similar proliferative activity appear to belong to two different groups based on FDG uptake, suggesting the influence of other factors [40]. In cultured human ovarian adenocarcinoma cells, FDG uptake is not related to proliferative activity but to the number of viable tumour cells [41]. In subcutaneously transplanted tumour cells, Kubota et al. [42] analysed the intratumoral distribution of FDG and tritiated deoxyglucose. Both tracers had a similar distribution pattern within the tumour with both autoradiographic methods. A maximum of $29 \%$ of glucose utilization was derived from non-tumoral tissue. It was concentrated in granulomatous tissue and macrophages infiltrating the areas surrounding necrotic tumoral tissue. High accumulation of FDG in the tumour is believed to represent high metabolic activity of the viable tumour cells [43, 44].

It is important to stress that FDG uptake by neoplastic tumours in vivo remains under the dependence of other physiological factors, such as tissue oxygenation, regional blood flow and peritumoral inflammatory reactions [45-48]. FDG PET therefore must be considered as a very sensitive technique, but a technique whose specificity is imperfect and must be compensated for by careful selection of patients and rigorous correlation with anatomical images (including image fusion, whenever possible) [49].

Other tracers designed to evaluate amino acid uptake (carbon-11 methionine) [44, 50-52], protein synthesis (" ${ }^{1} \mathrm{C}$-tyrosine) [53] or DNA synthesis and cellular proliferation $\left({ }^{11} \mathrm{C}\right.$-thymidine and ${ }^{18} \mathrm{~F}$-fluorodeoxyuridine) $[46$, 54] have been proposed as tumour imaging agents. However, less experience has been accumulated using these tracers. While theoretically attractive, they are more difficult to produce and usually do not provide the same image contrast that makes FDG so impressive (with the notable exception of ${ }^{11} \mathrm{C}$-methionine for brain tumours). Use of tracer modelling technique is required and in particular, labelled metabolites in blood and tissues have to be taken into account. For instance, no adequate model is yet available for ${ }^{11} \mathrm{C}$-thymidine while it is now recognized that a significant part of the signal in tissues is related to accumulation of ${ }^{11} \mathrm{CO}_{2}$ ! [55].

Kubota et al. [50, 51] have compared the tumoral uptake of methionine (using ${ }^{14} \mathrm{C}$-methionine in place of ${ }^{11} \mathrm{C}$-methionine) and FDG using the same tumour models or experimental conditions for both tracers. ${ }^{14} \mathrm{C}-\mathrm{Me}-$ thionine uptake within viable tumour cells is relatively more important than the uptake of FDG. Indeed, FDG is taken up not only by viable tumour cells but also by the peritumoral granulation tissue, by activated macrophages within the tumour and by cells at the periphery of necrotic tumoral tissue. These observations suggest that ${ }^{11} \mathrm{C}$-methionine could give false-negative results when 
studying tumours with few active tumoral cells but massive macrophage infiltration. On the other hand, during follow-up of therapy, and especially of radiotherapy, in the presence of numerous activated macrophages and prenecrotic tumoral cells, FDG could remain increased in the absence of proliferating tumoral cells. The choice between these two tracers therefore depends on the type of tumour studied and on the aim of the test. In general, to differentiate between benign and malignant tissues, FDG should provide more sensitive results than ${ }^{11} \mathrm{C}-\mathrm{me}$ thionine $[31,50,51]$.

A similar comparison has been performed by Minn et al. [44] using different models derived from three cellular lines from head and neck epidermoid epithelioma. Indeed, the proliferation kinetics of head and neck tumours has important implications concerning the irradiation schemes. The uptake of FDG and of ${ }^{14} \mathrm{C}$-methionine appears in that study to be well correlated to the pool of viable cells. Absolute methionine uptake, however, is smaller than that of FDG, especially during the exponential and plateau proliferation phases, leading to relative underestimation of the number of tumoral cells when using methionine. These two studies confirm the potential advantage of FDG for the study of the pool of viable cells. Methionine, on the other hand, appears superior for evaluation of the number of proliferative cells. ${ }^{1} \mathrm{C}$ methionine could prove more favourable for evaluation of therapeutic efficacy, especially after radiotherapy.

Other investigators have pointed out, however, that methionine, although a tracer of amino acid uptake, is not a tracer of protein synthesis, and they propose the use of ${ }^{11} \mathrm{C}$-tyrosine instead. ${ }^{11} \mathrm{C}$-tyrosine would indeed be better suited to kinetic modelling of protein synthesis, but experimental and clinical uses of this tracer are only beginning [56].

\section{Methodological considerations}

The field of view of the PET camera is usually quite limited as these instruments were initially developed for the heart and the brain, and because of cost constraints. It varies between 10 and $16 \mathrm{~cm}$ in most scanners, with the largest field of view for a single acquisition being in the order of $25 \mathrm{~cm}$. Most scanners consist of BGO or NaI crystals and the number of slices depends on the physical size of the sampling elements and/or on the size of the digital matrix [57-59]. Resolution typically varies between 4 and $6 \mathrm{~mm}$ FWHM depending on the performance of the unit. An important consideration is the achievement of isotropic resolution and avoidance of off-centre degradation, necessary for successful image reorientation. Effective clinical resolution can be further degraded by count statistics and the use of smoothing filters. It is more typically around $6-10 \mathrm{~mm}$ depending on the instrument used. The use of single-photon emission tomographic (SPET) cameras with high-energy collimators remains unproven in oncology [60] while the use of dual-head large field of view cameras with coincidence correction now appears feasible [61].

Instrument sensitivity is more important than count rate for whole-body PET and oncology as it allows optimal use of frequently limited tracer amounts, and directly influences scanning time. The advent of 3D-imaging capability has markedly increased the sensitivity of current scanners and allowed an increase in the signal to noise ratio while reducing the amount of tracers needed.

Whole-body imaging is performed by successively displacing the patient bed over $1 / 2$ to 1 time the field of view [62]. Some degree of overlap is preferable, especially in the 3D-mode, to even out $\mathrm{z}$-axis sensitivity changes due to varying effective axial incidence angle over the field of view and to avoid zip artefacts caused by patient motion or by overcompensation of sensitivity variations at the edges of the field. Use of bed displacement of $1 / 2$ the field of view interval does not prolong the acquisition time as sampling remains homogeneous over the whole body.

Attenuation correction is necessary for quantitative tracer uptake determination $[63,64]$. It is usually performed using transmission images. These are most necessary over the thorax, where important variations in tissue density are expected $[65,66]$. Transmission data are, however, less critical over the brain and the abdomen. In these regions, attenuation can be calculated using body contours assuming a uniform tissue attenuation. Errors resulting from this assumption may be less critical than errors resulting from incorrect attenuation measurements by inadequate (short, count deficient) transmission scans. Similar considerations have prompted the introduction of transmission image segmentation for attenuation correction in the thorax. Segmentation traces the contours of the patient as well as of the imaging table. It determines the limits of the lungs and optionally of the spine and substitutes a known attenuation coefficient for the measured attenuation correction. This approach decreases the artefacts produced by the statistical noise in the transmission image and allows a reduction in transmission imaging time. Routine attenuation correction is usually not performed in the whole-body mode and such an approach may be necessary for its routine implementation.

Currently quantitative data are usually obtained using detailed dynamic imaging followed by static imaging using pre-injection attenuation correction [67]. Another technique introduced to optimize acquisition time and scanner utilization is the use of post-injection and postemission transmission corrections. This approach is made possible by the use of a rotating rod source [68]. Knowledge of the position of the source allows exclusion of most of the emission events whose line of coincidence is not co-linear with the source. The rate of emission events co-linear with the source can be estimated by the use of a mock transmission source positioned at a fixed angle from the real source and a similar event rate can be subtracted. This approach has been validated 


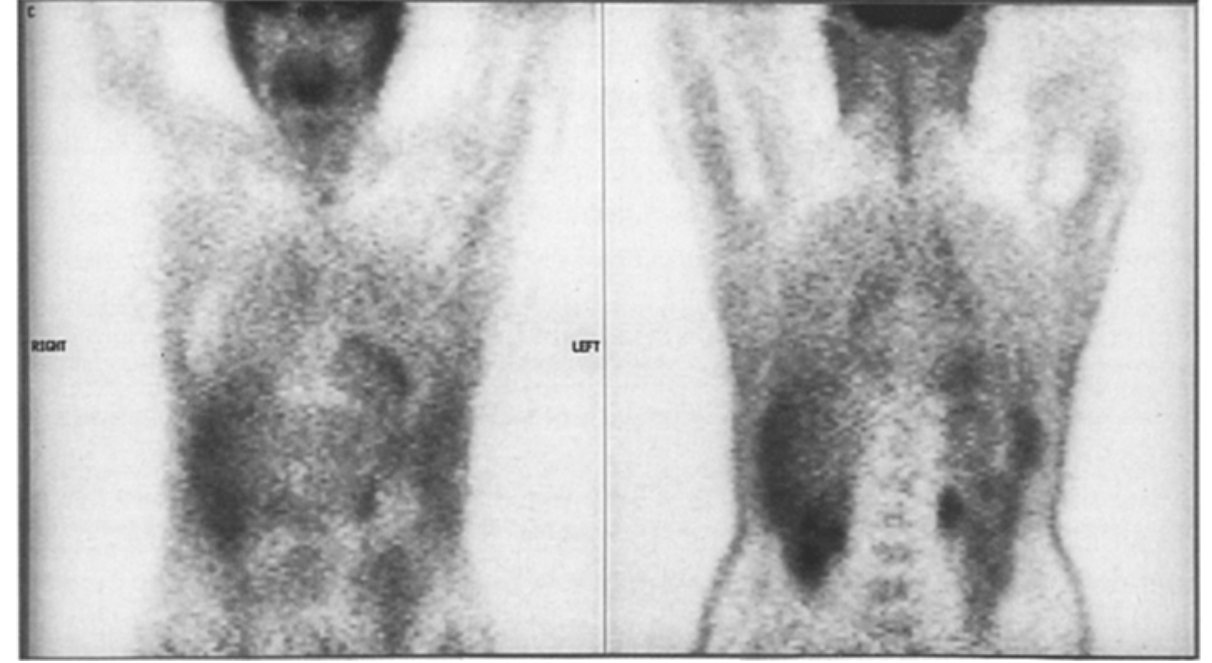

Fig. 1. Normal distribution of FDG uptake by phantom and patient studies. It allows significant shortening of total patient time in the scanner and decreases considerably motion artefacts in attenuation corrected images [69].

A high-energy single-photon emitter (cesium-137, $667 \mathrm{kev}$ ) has been proposed as a transmission source to increase count rate to the distant crystal [63]. Saturation of the nearby crystal is no longer a problem as true coincidence imaging is not performed ("coincidence" is between the source position and its interactions on a distant detector) and the near detectors are protected by shielding. Preliminary results indicate a considerable reduction in transmission acquisition time using this system. Another approach is the use of computed tomography to measure the transmission data. Technological advances have reduced the cost of CT and hybrid machines are now being considered. In addition, this approach could provide optimal matching between anatomical and biochemical images.

Visual qualitative assessment of whole-body PET imaging is usually quite satisfactory [70]. Yet quantification is desirable. The rate of tracer uptake over time can be determined using dynamic images. If the blood tracer activity over time is also available [obtained by arterial sampling or in a large vessel region of interest (ROI)], a compartmental modelling tracer kinetic approach can be used [32]. A three-comparment model is usually used with FDG. The Patlak-Gjedde graphical approach can also be applied using dynamic data to estimate the rate of influx of FDG in quantitative terms [71]. Both approaches require assumptions regarding the lumped constant. Yet this has not been assessed in tumours and would be difficult to determine given tumoral uptake heterogeneity.

Simple semi-qualitative analysis is now frequently performed using tumour to non-tumour uptake ratios or preferably by determining the standardized uptake ratio (SUV), which relates the concentration in the tumour to the average concentration in the body considered as unity. Generally the higher the value, the more likely it is that tumour is present. Conceptually simple, the SUV is more difficult to apply to whole-body than static imaging as its requires multiple corrections (for decay, attenuation, scatter, randoms, dead time, etc.) [70, 72-75]. Yet it remains poorly standardized as it is still dependent on many factors including glucose level, weight and fat body content, time after injection, ROI size and scanner resolution (partial volume effect) [76-78]. The SUV rises over time in most untreated tumours and standardization of imaging time is important in quantitative studies. SUVs from different institutions with different scanners or imaging protocols cannot necessarily be compared.

The normal distribution of the tracer is illustrated in Fig. 1. The uptake predominates in the brain, where the grey matter avidly concentrates FDG irrespective of the metabolic conditions. Myocardial uptake is variable and depends on substrate availability. The kidneys concentrate and eliminate FDG, which therefore accumulates in the urinary outflow tract and bladder. Moderate uptake is noted around the eyes, mainly in the oculomotor muscles, in the mucosal, muscular and lymph node tissue of the mouth, nasopharynx and pharynx, and in the liver, spleen and bone marrow. Activity varies markedly in the gastrointestinal tract. Some increase is usually noted in the region of the stomach, but colonic uptake can be quite significant, mainly around the hepatic and splenic angles and in the sigmoid [79, 80]. Muscular activity is also quite variable [77] and can be prominently increased in the case of muscle tension or utilization around the time of injection. Complete rest (no walking, no reading, no chewing, no speaking) is indicated and the use of diazepam may be necessary in some tense subjects to avoid muscle uptake artefacts. Uptake is low in fat tissue. Uptake in the lung is also low but appears elevated on images without attenuation correction because of the low pulmonary density. Also the activity of the skin is overestimated on uncorrected images but may provide a convenient landmark for image interpretation. Image artefacts can result from technical defects, transmission image misalignment, patient motion or the pres- 
ence of an artefactual or normal hot spot on the image. They can frequently be prevented by careful attention to patient preparation. The patient should be fasting for a minimum of $4-6 \mathrm{~h}$ before the injection time to reduce serum insulin levels to near basal quantities. Water is permitted, however, to promote diuresis, and coffee might in fact increase fatty acid level and decrease myocardial uptake (Maisey, personal communication).

We recommend the i.v. cannular administration of between 100 and $400 \mathrm{Mbq}$ of FDG in order to minimize the risk of extravasation and lymphatic migration. The injection site is chosen away from expected pathologic zones. As mentioned earlier, the patient should be in complete rest at the time of injection and during the waiting period. We routinely perform scanning 60-90 min after injection to increase tumoral to background contrast. This delay also allows better emptying of the urinary tract and voiding of the most concentrated urine before scanning. Imaging of the pelvis nevertheless presents significant problems, and forced diuresis (using $20 \mathrm{mg}$ i.v. furosemide) is in our opinion necessary. The bladder should be emptied before the examination to eliminate the concentrated urine but we prefer to work with a bladder full of weakly concentrated urine whose spherical limits are clearly recognized rather than with an "empty" bladder whose activity cannot be precisely delimited. Often patients receiving diuretics require bladder catheterization to tolerate the duration of the scan. In these cases, we empty the bladder $10 \mathrm{~min}$ before scanning the pelvic area, then clamp the line and let the bladder fill until scanning. Typically scanning is started from the inguinal region upwards to minimize bladder activity. Artefacts from hot spots also result from the use of filtered backprojection algorithms for image reconstruction. They can be significantly reduced by the use of iterative reconstruction algorithms. The increase in computing power facilitates the use of these technique nowadays and they are recommended especially in the pelvis. Image interpretation can also be markedly facilitated by image fusion. The concomitant analysis of metabolic and structural information provides anatomical references frequently lacking in PET and a more precise estimation of lesion size, which is frequently a critical parameter in image interpretation (for instance to estimate the influence of the partial volume effect) [81].

\section{Clinical indications for FDG in oncology}

Let us first examine the clinical indications for FDG imaging as they present along the course of the cancerous process $[6,62,82-86]$. We shall later discuss these indications in detail, tumour by tumour.

\section{Differential diagnosis}

FDG PET has proved useful in the differential diagnosis of the solitary pulmonary nodule, the differentiation of pancreatic carcinoma versus mass-forming pancreatitis and the diagnosis of breast carcinoma in selected cases of mammography and/or biopsy failure (in particular in dense breasts and in implants). In other indications, such as the differential diagnosis of thyroid cancer in patients with cold nodules, PET may not be cost effective in comparison with a standard diagnostic strategy.

\section{Initial (preoperative) staging of cancer}

The importance of initial staging for optimal cancer management cannot be overemphasized. The success of therapy indeed depends on adequate staging. The role of diagnostic techniques in staging is, however, variable and depends on the efficacy of the screening methods for that cancer, on the propensity of the tumour for early metastases and on the role of surgery itself in staging. Initial staging by FDG has proven useful in lung cancer, melanoma and sarcoma. Initial staging in lymphoma is probably indicated as a baseline for therapy follow-up. FDG PET staging is also probably indicated in selected cases of other tumour types, especially when the tumour is at an advanced stage or when metastatic lesions are suspected by conventional imaging or suggested by high levels of tumour markers. Indeed, in these cases, FDG PET can provide sensitive whole-body screening. This is certainly the case for ovarian, head and neck and pancreatic carcinomas. Initial evaluation in colorectal cancer has been suggested, but results are inconclusive. Initial staging in breast carcinoma has been the subject of several studies. Although initial results were optimistic, recent reports in larger non-selected groups of patients have suggested that the sensitivity for the detection of axillary node metastases is around $75 \%$. FDG PET can, however, depict internal mammary node metastases that are not routinely explored by the surgeon. At this stage, the role of PET in the staging and prognostic evaluation of breast carcinoma remains to be clarified.

Another indication related to initial staging is the search for the site of the primary tumour in patients with known metastases. According to Kole et al. [87], the success rate of whole-body PET in this indication is approximately $25 \%$.

\section{Differentiation of scar and residual disease}

Differentiation of scar and residual or recurrent disease is a frequent indication for PET and one of the first to be documented [88]. In 1988, Di Chiro et al. showed the value of FDG PET in distinguishing radiation necrosis from recurrent tumour in the brain [89, 90]. A similar differentiation has been reported to be useful in the 
lungs and in head and neck tumours. Indeterminate pelvic masses on CT are frequent in the follow-up of colorectal cancer and require biopsy evaluation. Strauss et al. described the value of PET for distinguishing scar from recurrence [91]. The use of an iterative reconstruction technique to avoid bladder artefacts was essential in their success. FDG has also proven useful in the evaluation of residual masses after therapy for lymphoma. Gallium has previously been found useful in this indication but FDG, unlike gallium, does not require a baseline examination to verify that the tumour indeed accumulates the tracer.

\section{Demonstration of suspected recurrences}

Other cases of suspected recurrence occur when tumour markers increase or when the patient presents general or local clinical signs suggestive of tumour recurrence. Tumour markers are used routinely to follow up patients with colorectal, ovarian, breast, lung, thyroid or pancreatic cancers, etc., and in many cases conventional imaging fails to detect the recurrence because of its small size or its occurrence at a distance from the initial site. Several studies have concentrated on the value of PET for the detection of early recurrences in such cases, based on its high sensitivity and its whole-body capability. Indeed, whenever a recurrence is confirmed, the extent of recurrence becomes the next question as the clinician ponders the therapeutic options.

The impact of PET on management, avoiding unnecessary surgery, allowing more complete surgery or allowing surgery when it had seemed contra-indicated, forms the basis of its cost-effectiveness [92].

\section{Follow-up of therapy}

FDG PET has been shown to be useful in evaluation of the early therapeutic response. FDG uptake can be markedly diminished or even completely suppressed after one or two cycles of chemotherapy, well before tumour mass can be shown to have decreased by conventional imaging. With the use of quantification, this technique has wide indications and is of interest for most cancers submitted to chemotherapy or radiotherapy (lymphoma, breast tumours, sarcoma, ovarian tumours, germ cell tumours, head and neck carcinomas, lung cancer, colorectal cancer, hepatic metastases, etc.). Early determination of therapeutic resistance is also important to avoid the toxicity of an ineffective therapy and to allow selection of a new therapeutic regimen.

\section{Prognostic value of FDG uptake}

The prognostic value of FDG uptake has also been stressed by Alavi et al. [93] in cerebral tumours and by
Reisser et al. [94] in head and neck tumours; tumours with higher FDG uptake appear more aggressive and to develop faster. The extent of metastatic involvement as depicted by PET and the evaluation of the therapeutic response also have prognostic significance.

\section{Results in selected organs and cancer types}

\section{Lung tumours}

Differential diagnosis. Lung cancer is one of the most prevalent cancers in the industrialized world and a leading cause of cancer death in both men and women. Lung cancer may present as a solitary pulmonary nodule and be detected by conventional chest radiography. The incidence of these nodules is high: 130000 new cases per year in the United States, or 52 cases per 100000 inhabitants. Despite the progress of imaging and in particular of computed tomography (CT), few criteria can reliably differentiate benign from malignant nodules [95]. The generally accepted criteria of benignity are:

1. Detection of a benign pattern of calcification (central, diffuse, popcorn) in the nodule

2. Stability of the nodule over the preceding 2 years

3. A very low probability of malignancy, based on age, particularly if exposure to tobacco smoke has been minimal

The clinician must therefore frequently choose between expectation, potentially dangerous in malignant lesions, and invasive diagnostic or therapeutic measures carrying high morbidity and also some mortality risk even when a benign lesion is present. It is currently estimated that $50 \%-60 \%$ of solitary pulmonary nodules are benign [96]. Yet despite current advances in morphological imaging the number of resected nodules proving benign remains high $(20 \%-40 \%$ of the total), indicating that a substantial number of patients are needlessly exposed to peri- and postoperative complications [97].

Considerable experience is now available regarding the diagnostic value of FDG PET in solitary pulmonary nodules. Table 1 summarizes the main reported studies, including the date of publication, the number of patients studied, and sensitivity and specificity [70, 92, 98-107]. As can be seen, a high sensitivity has been achieved by all groups (average $96 \%$ ). The specificity is also high but varies slightly more and probably depends on the local prevalence of the known causes of granulomatous disease responsible for false-positive cases (tuberculosis, histoplasmosis, aspergillosis, coccidiomycosis, blastomycosis, etc.).

We have prospectively studied 50 patients with undetermined solitary pulmonary nodules. Results of wholebody PET (neck to mid abdomen) were correlated to the surgical or transthoracic needle aspiration biopsy of the lesion (Fig. 2). Thirty-three pulmonary cancers were correctly identified while 15 of 17 benign nodules were 
Table 1. Studies on the use of FDG PET in solitary pulmonary nodules

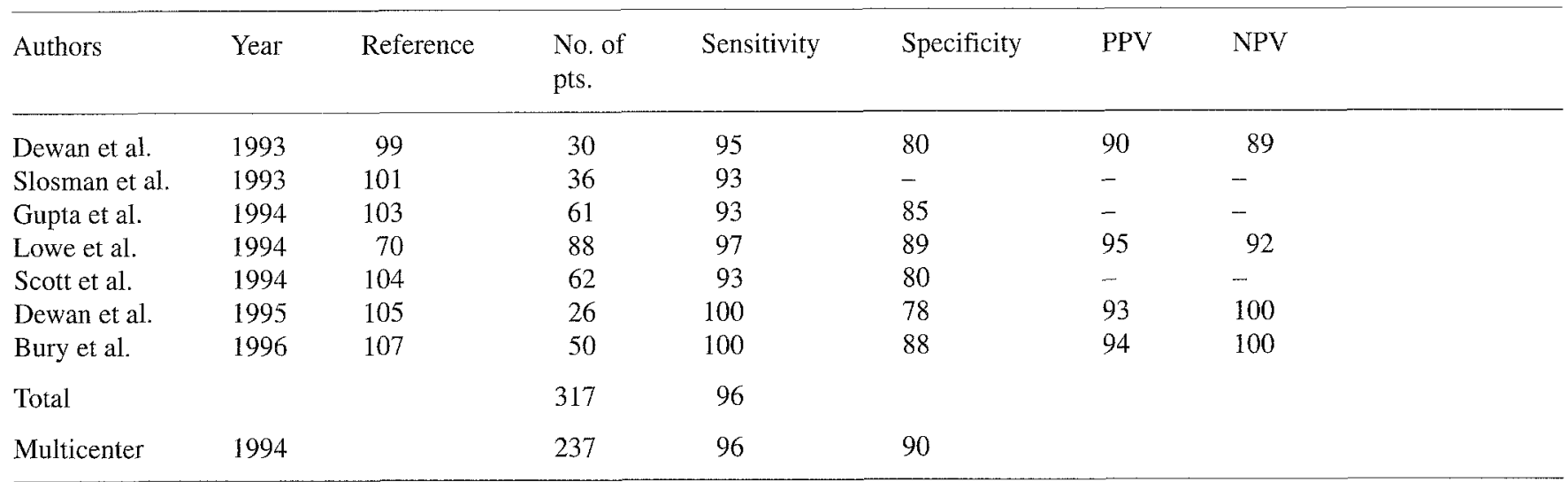

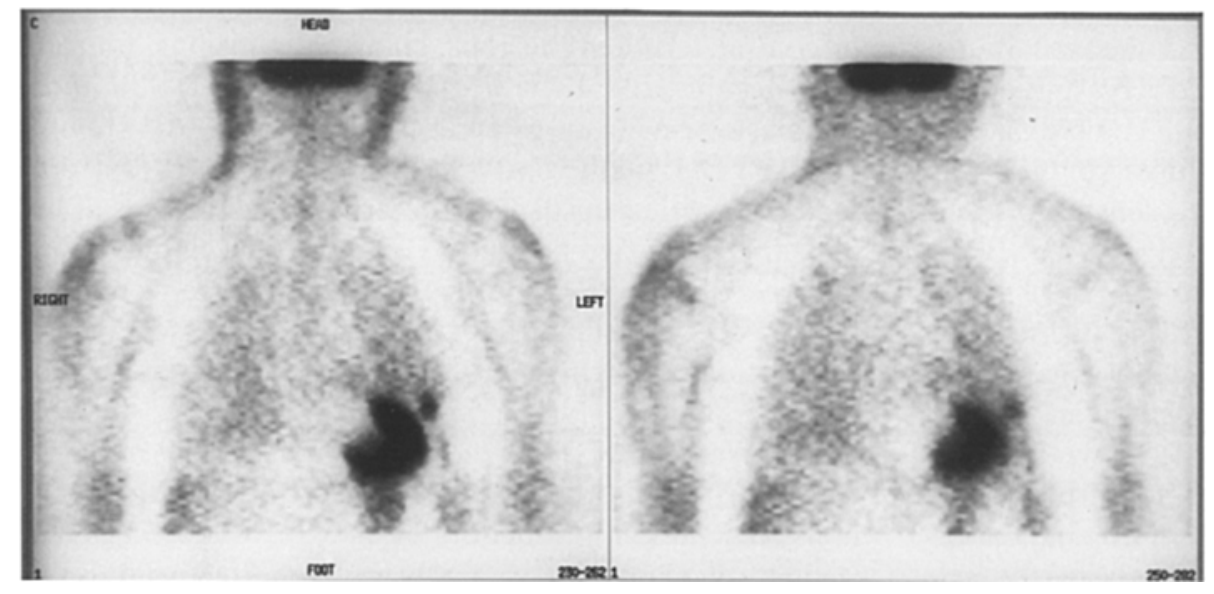

Fig. 2. Malignant solitary pulmonary nodule (adenosquamous cell carcinoma). Chest X-ray and CT showed an unspecified $1.7-\mathrm{cm}$ solitary pulmonary nodule recognized. There were two false-positives (one case of active tuberculosis and one case of pseudotumoral anthracosilicosis with partial necrosis and perinecrotic inflammation). At present, our positive predictive value is 94\% while our negative predictive value is $100 \%$ [106-108].

Dewan et al. have compared the use of PET with a diagnostic strategy based on $\mathrm{CT}$ and transthoracic fineneedle aspiration (TTNA) biopsy [105]. In 35 lung lesions PET correctly identified all 26 malignant lesions as well as seven of the nine benign lung lesions, but produced two false-positive readings. In contrast, TTNA was positive for malignancy in 21 lung lesions (five false-negative) but did not result in false-positive findings. The overall predictive accuracy was $94 \%$ for PET and $86 \%$ for TTNA but the latter resulted in a pneumothorax in 16 patients while nine patients $(26 \%)$ required chest tube aspiration. This complication rate appears fairly typical as compared with other reports [109].

Use of FDG PET for differentiation of solitary pulmonary nodules could lead to significant savings in addition to reducing the number of complications during management $[92,105]$.

Application of the quantitative technique to the diagnosis of solitary pulmonary nodules has been evaluated.
It appears effective and certainly increases the objectivity of analysis but it does not appear to significantly improve the diagnosis as compared to visual analysis [64, 70]. Reproducibility is maximal for SUV (SUV related to lean-body mass corrected for blood glucose concentration) and for $K_{\mathrm{i}}$ (slope of the graphical analysis as defined by Patlak). Parameters derived from compartmental modelling have been less reproducible [74].

Preoperative staging. In patients with known lung carcinoma, the results of staging both within and outside the thorax are the key in determining the operability. Demonstration of a unilateral hilar adenopathy is not a contra-indication to surgery if the nodes can be resected with the primary tumour. By contrast, extensive mediastinal involvement, contralateral lymph node involvement, and pleural or distant metastases should contra-indicate surgery due to the surgical morbidity and the poor prognosis.

Several studies have evaluated the role of FDG PET for staging lung carcinoma. These studies must be separated into two groups. Some investigators have used focal techniques and have concentrated on hilar and mediastinal lymph node staging, while others have used whole-body techniques and have evaluated extrathoracic 
Table 2. Staging of lung cancer by FDG PET

\begin{tabular}{lcrrrl}
\hline Authors & Reference & $\begin{array}{l}\text { No. of } \\
\text { pts. }\end{array}$ & Sensitivity & Specificity & Comments \\
\hline Berlangieri et al. & 110 & 22 & 90 & 100 & Med. lymph node \\
Sasaki et al. & 111 & 9 & 86 & 100 & Med. lymph node \\
Patz et al. & 112 & 21 & 100 & 73 & Med. lymph node \\
Wahl et al. & 49 & 19 & 82 & 81 & Med. lymph node \\
Bury et al. & 119 & 30 & 85 & 81 & Med. lymph node \\
Buchpiguel et al. & 114 & 26 & 93 & 83 & WB \\
Lewis et al. & 115 & 34 & 199 & 97 & WB \\
Valk et al. & 117 & 62 & 85 & 93 & WB \\
Bury et al. & 122 & 61 & 100 & 95 & WB \\
\hline
\end{tabular}

Med., Mediastinal; WB, whole body metastases as well (Table 2) [49, 110-119]. The reported sensitivity for lymph node staging in non-small cell lung cancer varies from $82 \%$ to $100 \%$ and the specificity from $73 \%$ to $100 \%$. We have prospectively studied 50 patients prior to thoracotomy $[119,120]$. The prevalence of hilar or mediastinal lymph node involvement was $58 \%$. We have obtained values of $85 \%$ (sensitivity) and $81 \%$ (specificity) with a positive predictive value (PPV) of $85 \%$ and a negative predictive value (NPV) of $81 \%$; by comparison, these four figures with $\mathrm{CT}$ were $64 \%$, $68 \%, 67 \%$ and $65 \%$ respectively. It is interesting to note that CT both underestimated and overestimated the extent of disease, so that in comparison PET would have contributed both to cancellation and to confirmation of surgery as a therapeutic modality. PET in this indication appears to supply information currently only partly provided by mediastinoscopy. Given the high sensitivity of PET for mediastinal staging, a negative result should allow one to proceed to surgery without mediastinoscopy. Considering the $15 \%-20 \%$ false-positive rate however, a confirmatory mediastinoscopy remains indicated in patients with less specific uptake patterns (mild uptake, moderate uptake and nodal enlargement, or discordant PET and CT results).

Whole-body FDG PET also contributes to significant management changes as first assessed by Lewis et al. in 34 patients [115]. In this study, unsuspected malignant metastatic lesions were recognized in ten patients (12 extrathoracic and eight thoracic sites). Management changes were noted in 14 patients. Six $(+2)$ patients were classified as unsuitable for surgery while eight patients with equivocal findings were found to have single PET lesions. A frequent location of suspected metastases are the adrenals, where $\mathrm{CT}$ detects many non-specific abnormalities. PET can confirm or exclude such metastases effectively [121]. Our own results confirm the data of Lewis [122]. We have studied 61 patients by conventional imaging and whole-body PET for staging of nonsmall cell lung carcinoma. When CT or PET study suggested metastatic disease, confirmation was obtained by biopsy or clinical or radiological follow-up. As compared to CT, PET correctly changed the $\mathrm{N}$ stage in 13 patients $(21 \%)$ : it increased the stage in six patients and decreased it in seven. Presence of metastatic lesions $(n=28)$ was confirmed in 19 patients: eight homolateral or contralateral lung lesions, six hepatic lesions, four adrenal lesions, five bone lesions, one pleural lesion, three lymph node metastases and one skin lesion. All showed intense FDG uptake on PET. In contrast to CT, PET correctly identified unsuspected extrathoracic lesions at ten distant sites in five patients. There were no known falsenegative distant PET findings. However, there were three false-positive distant PET findings (versus seven with conventional imaging) corresponding to moderate uptake in inflammatory lymph nodes (two axillary and one lung). We believe that the whole-body PET technique can improve the diagnostic accuracy in the staging of non-small cell lung cancer.

Valk et al. [117], in a recently reported study concerning subsets of 76 and 99 patients, also noted that PET correctly changed the nodal stage as determined by CT in 18 staging evaluations ( $24 \%$ ), increasing the stage in eight patients and decreasing it in 11, including one false-negative. PET changed the metastasis stage in 30 patients: previously unsuspected distant metastases were demonstrated in 11 patients while normal PET findings were obtained at distant sites of CT abnormalities in 19 patients (one false-negative).

Detection of cerebral metastases. The detection of cerebral metastases is also possible using FDG PET but a dedicated cerebral PET sequence is probably needed. Larcos and Maisey [123] have tested the efficacy of a supplementary 10-min brain sequence in patients with various malignancies. Cerebral metastases were reported in four patients $(1.5 \%)$, only two of which were unsuspected prior to the PET scan. The authors conclude that "routine" screening for cerebral metastases in patients with suspected malignancy may not be clinically useful.

Demonstration of recurrences; follow-up of therapy. Experience is also available regarding the use of PET to assess lung tumour response to therapy and in the detection of recurrences after successful initial therapy. Abe et al. [124] demonstrated that patients judged to have a clinically complete response to radiotherapy or chemo- 
therapy had negative PET results while results remained positive in patients with a partial response. Knopp et al. as well as Abe et al. suggested that PET results were the most reliable indicators of the patient's prognosis when compared with clinical parameters and tumour markers $[124,125]$. Others have also reported a high diagnostic accuracy of FDG PET in the detection of tumour recurrence $[113,126-130]$.

PET in pleural disease. In a related subject we have also shown the value of PET in the assessment of patients with malignant or non-malignant pleural effusion [131]. We have investigated the utility of FDG PET for the aetiological diagnosis of pleural disease in 25 patients. Sixteen had malignant pleural disease (three primary mesotheliomas and 13 cases of metastatic pleural involvement) while nine had non-malignant pleural disease (three benign tumours and six pleural infective processes). All three mesotheliomas and 11 cases of metastatic involvement displayed intense FDG uptake. Two patients with metastases and two with infection had moderate uptake. Seven patients with benign lesions had no uptake. PET appears useful to reduce the number of both open pleural biopsies and limited thoracotomies for benign pleural disease. Patients without FDG uptake appear unlikely to have cancer. Patients with mild uptake require biopsy, potentially directed by PET data, for differential diagnosis. In patients with intense uptake, the PET data can also be used for biopsy guidance for histological confirmation when needed.

Similar data have been reported by Lowe et al. [132] in 23 patients with biopsy-proven diagnosis. Six patients had benign pleural abnormalities, including four with SUR values below 2.5 . Of 17 patients with malignant disease, 15 had SUV values above 2.5. Two patients with active infection in the pleural space also had increased FDG uptake.

The role of FDG PET in patients with small cell lung carcinoma has only rarely been discussed. FDG nevertheless appears to have some potential role in differentiating limited disease from extensive disease as well as in the follow-up of therapy [125].

In summary, results in lung cancer provide evidence for many different clinical indications for FDG PET at the various stages of the disease, including differential diagnosis of solitary nodules, initial preoperative staging of the nodal extent of non-small cell lung cancer, detection of unsuspected metastases, differentiation or demonstration of suspected recurrence, and therapeutic follow-up [133-136].

\section{Tumours of the gastro-intestinal tract}

Colorectal carcinoma

Colorectal carcinoma is a frequent tumour and presents successive diagnostic problems at the time of initial di- agnosis, staging and assessment of recurrence following therapy.

About $70 \%$ of patients have resectable tumours initially but recurrences do occur in one-third of patients, most commonly during the first 2 years after operation. Such recurrences can be locoregional, but more often distant or generalized metastases occur and currently only about one-quarter of patients with recurrences can be cured by re-intervention [137].

The techniques available for the staging and assessment of potential recurrences lack sensitivity and precision and frequently result in diagnostic and therapeutic delays. Tumour markers, although useful, have only a $59 \%$ sensitivity and an $84 \%$ specificity for recurrences [138]. Barium enema detects local recurrence but is insensitive $(49 \%)$ for overall recurrence detection [139]. Similar results are reported for colonoscopy. CT is useful for liver metastases but not nodal involvement [140]. Numerous patients with negative CT have a non-resectable tumour at the time of surgery.

FDG is avidly concentrated in colorectal carcinoma and current studies indicate an important role of PET in the evaluation of this cancer. The first report dates back to 1982 , when liver metastases of colorectal cancer were visualized in a feasibility study of FDG and PET at Brookhaven National Laboratory [141]. Since then a number of studies have been published, confirming the value of the technique.

Preoperative detection and staging. Detection of the primary tumour at the time of diagnosis appears possible but insufficient data exist to suggest that PET might play a role in staging at that time although it has an accuracy superior to that of CT $[142,143]$ (PPV is 93\% and NPV $50 \%$ for FDG PET versus $100 \%$ and $27 \%$, respectively, for CT) [142]. Rather, the clinical and economic impact of PET appears more clearly in the evaluation of postoperative recurrence.

Detection of locoregional recurrences. Patients with presacral masses and suspected local recurrences were first studied by the group from the German Cancer Research Centre in Heidelberg. In several successive studies, these investigators $[91,144]$ demonstrated the value of PET in differentiating scar tissue and tumour in this setting, a finding later confirmed by Ito et al. and Schiepers et al. $[145,146]$ (Table 3 ). In contrast, when a presacral mass

Table 3. Local pelvic recurrence: comparison of FDG PET and CT (data from Schiepers et al. [146]: 74 patients, 45 positive cases)

\begin{tabular}{lll}
\hline & Sensitivity $(\%)$ & Specificity $(\%)$ \\
\hline PET & 93 & 97 \\
CT & 60 & 72 \\
\hline
\end{tabular}

PET: 2 false-negatives, 1 false-positive and 1 indeterminate 
Table 4. PET in colorectal carcinoma: staging of recurrent disease after initial therapy

\begin{tabular}{lllll}
\hline Authors & Reference & No. (pts., sites) & Sensitivity (\%) & Specificity (\%) \\
\hline Gupta et al. & 149 & 18 & 100 & 86 \\
Multicentre & 155 & 59 & 93 & 78 \\
Schiepers et al. & 146 & 76 & 94 & 98 \\
Pounds et al. & 151 & 57,78 & 95 & 87 \\
Daenen et al. & 154 & 19,29 & 95 & 67 \\
\hline
\end{tabular}

is identified on CT, it is very difficult to diagnose its origin: scar, fibrotic tissue or tumoral recurrence. Biopsy is needed but is only useful when positive as false-negative results are frequent and due to unavoidable sampling errors [147].

Transrectal ultrasonography (US) can demonstrate the depth of involvement of distal lesions as well as the presence of pararectal adenopathies. PET in this indication appears very useful and clearly superior to CT $(95 \%$ diagnostic sensitivity) but it has not been systematically compared with rectal US [91, 146]. It has the advantage, however, that the pelvic study is only one part of the whole-body survey.

Staging of patients with suspected or demonstrated recurrences. Results demonstrating the value of FDG PET in the identification of patients with isolated resectable lesions and in distinguishing them from patients with disseminated metastases have came from the group in Leuven, using the PET whole-body technique. Schiepers et al. evaluated 76 patients presenting with or suspected of having recurrent local or distant colorectal cancer [146]. The accuracy of PET for focal disease was $95 \%$, showing it to be superior to $\mathrm{CT}$ of the pelvis $(65 \%)$. The accuracy of PET for liver metastases (98\%) compared favourably with that of CT or US (93\%). Unexpected extrahepatic metastases were detected in 14 locations in ten patients. In a previous study on 35 patients, Beets et al. from the same group, evaluated the clinical impact of PET on management [148]. Sixteen patients presented with "resectable" metastases, eight with resectable pelvic recurrences, eight with a presacral mass of uncertain nature and three with an isolated increase in the carcinoembryonic antigen (CEA) level. PET affected the management decision in 7 of the 16 patients with metastatic disease; it detected additional lesions in two patients with pelvic recurrences as well as the site of the disease in two of the patients with an increased CEA level. Overall, PET affected management in 14 of the 35 patients. Falk et al. [142], Gupta et al. [149, 150], Pounds et al. [151] and Bohdiewicz et al. [152], as well as data from our own group [154], have also stressed the value of whole-body PET for staging recurrent disease in colorectal carcinoma (Table 4 ).

A multicentre study organized by the Institute for Clinical PET has examined the issue of cost-effectiveness in colorectal carcinoma based on a survey of 14 PET centres and a review of 267 colorectal cancer pa- tient records [155]. This preliminary report suggests a large potential saving based on the elimination of exploratory laparotomies and on a reduction (from $20 \%$ to $10 \%$ ) in the number of resections with curative intent (Fig. 3).

Evaluation of therapy. In 1991, Haberkorn et al. [156] evaluated patients with known recurrent disease prior to and after radiotherapy. FDG tissue levels tended to fall after therapy but changes in uptake parameters were not able to accurately predict therapeutic responses in individual patients. The authors suggested the potential role of radiation injury and of the inflammatory reaction in these results. Inflammation and metabolically active residual tumour tissue cannot be distinguished early after therapy.

In another report in 21 irradiated patients, Engenhart et al. [157] found that residual FDG uptake indicated the presence of residual tumour and a poor therapeutic response. PET was the earliest indicator of local relapse. The use of ${ }^{18} \mathrm{~F}-5$-fluorouracil in the therapeutic evaluation of patients with colorectal cancer is beyond the scope of this review.

\section{Pancreatic carcinoma}

Among gastro-intestinal cancers, pancreatic carcinoma has the worst prognosis. This may result from the difficulties encountered in the diagnosis of this cancer, which manifests only with non-specific clinical symptoms and with indirect signs on routine structural imaging (CT or US) $[158,159]$. Many nuclear medicine techniques have been proposed in the past to visualize the pancreas but studies performed with amino acids or blood flow tracers lack specificity for tumour visualization. Indeed, these tracers also accumulate in the normal pancreas and cancerous lesions usually appear as cold spots. Lesions of other aetiologies, however, also correspond to cold spots and this finding is not specific [160-162].

Several groups, predominantly from Japan and Germany, have evaluated the role of FDG PET in the differentiation of pancreatic adenocarcinoma from benign chronic pancreatitis and mass-forming pancreatitis [163-169]. Results indicate a sensitivity of ca. $94 \%$ with a specificity varying from $78 \%$ to $90 \%$ (Table 5 ). The optimal SUV cut-off varies between studies but is rather low (ca. 2) as glucose uptake in the normal pancreas is 


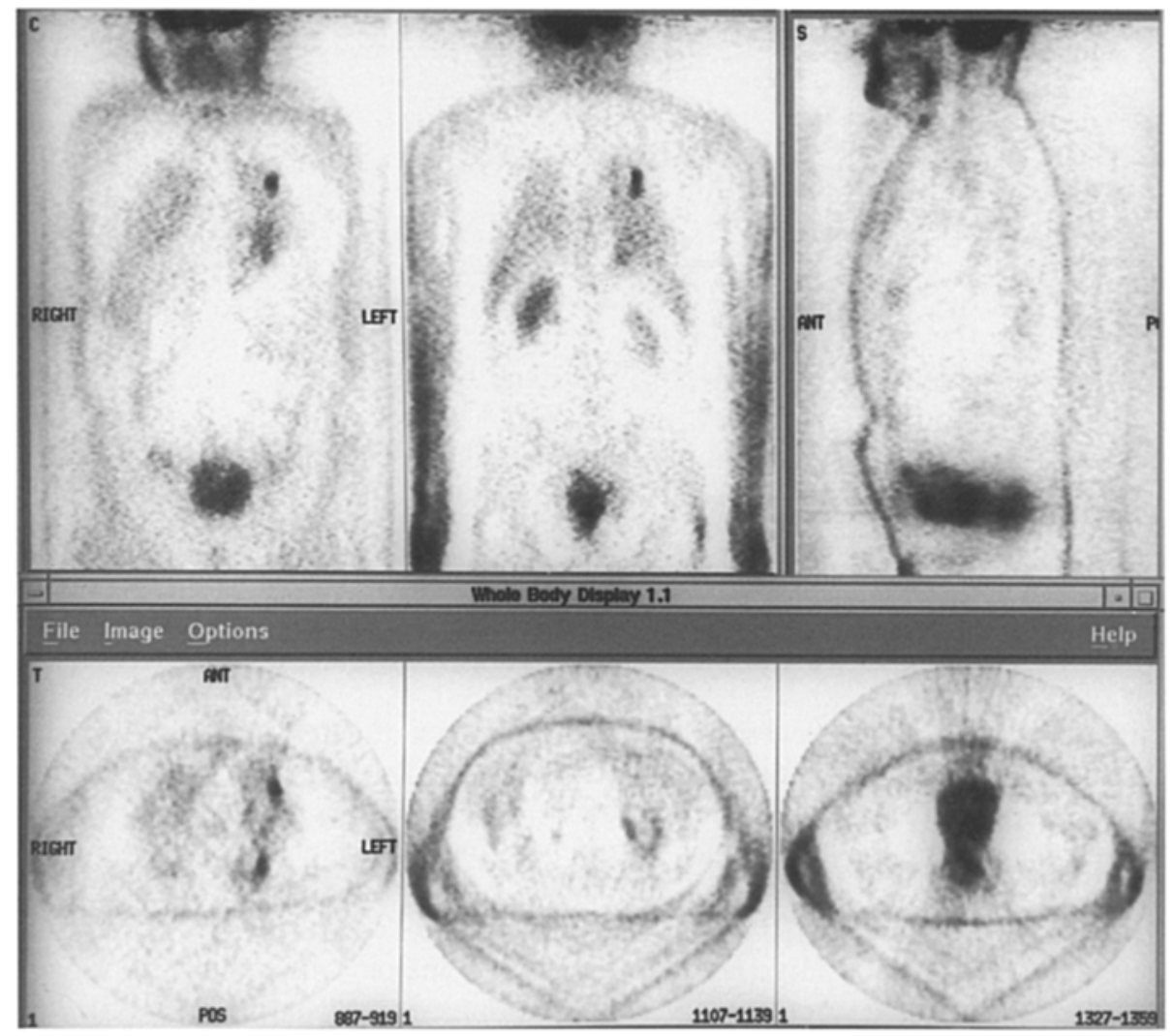

Fig. 3. Local relapse of previously operated rectal carcinoma. PET also demonstrates lung metastases

Table 5. FDG PET evaluation in pancreatic tumours

\begin{tabular}{lllll}
\hline Authors & Reference & $\mathrm{n}$ & Sensitivity $(\%)$ & Specificity(\%) \\
\hline Bares et al. & 163 & 40 & 92 & 84 \\
Inokuma et al. & 165 & 46 & 94 & 82 \\
Friess et al. & 164 & 80 & 94 & 88 \\
Stollfuss et al. & 168 & 73 & 95 & 90 \\
\hline
\end{tabular}

also low. On rare occasions, uptake in the site of pancreatitis is markedly elevated; generally, however, it is only slightly higher than in normal controls. Visual criteria use discrete focal elevated uptake as evidence for cancer, while diffuse or background level activity is taken as evidence for chronic pancreatitis or normal tissue. Bares et al. [163] first commented on the importance of adequate blood glucose control for optimal FDG uptake by the tumour. Indeed, glucose competes with FDG for transport and a high level of plasma glucose could inhibit FDG uptake within the tumour. Bares suggested this competition to be a possible cause of false-negative results, but the four patients with false-negative findings reported by Stollfuss did not have diabetes or elevated glucose levels [163, 168].

Evidence of metastatic extension of pancreatic carcinoma, lymph node involvement or liver metastases can be appreciated on PET images. However, no systematic study has yet been reported on the value of PET in this indication.
Gastric and oesophageal tumours

Little information is available on the role of FDG PET in the evaluation of gastric and oesophageal tumours [150, 170, 171]. In our limited experience, the ability of FDG PET to visualize the primary tumour is excellent. Its value in assessing the extent of the disease, progression to contiguous structures, nodal involvement or hepatic metastases has not been systematically examined yet, to our knowledge.

Liver metastases and hepatomas

Cancers of the digestive tract, colorectal carcinoma, pancreatic cancer, gastric or oesophageal tumours and cancer of the biliary tract demonstrate a high prevalence of haematogenous liver metastases, as do breast cancer, ovarian cancer, lung cancer, etc. Current diagnostic modalities (mainly US and CT) have suboptimal accuracy and many studies are reported as inconclusive [172]. Bi- 
Table 6. FDG PET evaluation of liver metastases

\begin{tabular}{lrlrrl}
\hline Authors & Year & Reference & No. & Sensitivity (\%) & Specificity (\%) \\
\hline Gupta et al. & 1993 & 175 & 14 & 92 & - \\
Shields et al. & 1995 & 176 & 8 & 100 & - \\
Schiepers et al. & 1995 & 146 & 80 & 94 & 100 \\
Hustinx et al. & 1996 & 177 & 62 & 97 & 87 \\
\hline
\end{tabular}

phasic spiral CT with images of the arterial and venous phase has shown promise for hepatocellular carcinoma and might be more useful in detecting hepatic metastases [173, 174]. Magnetic resonance imaging (MRI) may also be more sensitive than standard CT techniques.

Several studies have analysed the value of FDG PET in detecting liver metastasis (Table 6) [146, 175-177]. We have analysed 62 patients with malignant including tumours and 30 patients with evidence of at least one liver metastasis (histopathological confirmation in $14 \mathrm{pa}-$ tients, clinical confirmation in 16 patients). Negative cases were established by pathology $(n=4)$, peroperative US $(n=12)$ or clinical follow-up $(n=16)$. Agreement between metabolic and structural imaging (CT/US) occurred in $42 / 62$ patients (68\%). FDG was correct in $15 / 20$ discordant cases. FDG was false-positive in four cases and false-negative in one case.

Schiepers et al. [146] report a $98 \%$ accuracy for FDG PET detection of liver metastases (of colorectal cancer) versus $93 \%$ for CT/US (FDG was positive in 33/35 cases with metastases, and negative in $48 / 48$ cases without metastasis).

The image contrast between the uptake within liver metastases and that in normal tissue increases over time as a result of the high level of glucose-6-phosphatase activity within normal liver tissue. This results in decreased ${ }^{18} \mathrm{~F}$ radioactivity in normal tissue over time and in greater visibility of the lesion $[158,178]$. It is therefore appropriate to perform FDG liver imaging in patients with suspected liver metastases approximately 90 min after FDG injection. Attenuation correction remains possible in these cases if the transmission studies are performed after the emission study, as is nowadays possible, or if the attenuation correction is calculated using the body contour rather than based on transmission data. In the latter case, imaging of the patient with his arms out of the scanner is essential for adequate performance.

While delayed imaging improves contrast between liver metastases and normal liver, this is probably not the case in at least some patients with hepatoma. Indeed, while a large fraction of hepatomas are well imaged by FDG PET as hot spots relative to the liver, up to half of the tumours cannot be detected as regions of increased tracer uptake compared with normal liver [34, 179-182]. This latter patient group appears to retain a high dephosphorylation rate within the tumour cells. Enomoto et al. [180] have suggested that kinetic modelling could be used to better characterize hepatoma. In 35 patients with liver lesions confirmed by surgery, they analysed tracer kinetics using the Sokoloff model [32]. $k_{3}$ was correlated with tumour hexokinase content and the presence of cancer. Patients with hepatoma and a high $k_{4} / k_{3}$ ratio appeared to have the best survival.

\section{Lymphomas}

Several reports have shown the feasibility of imaging lymphomas using FDG [183-190]. This approach is of particular interest as metabolic imaging does not face the difficulties of structural imaging modalities in defining the presence and extent of lymphomatous tumours. CT and MRI require perturbation (e.g. space occupation) or enlargement (e.g. nodal) of anatomical structure to suggest tumour, and abnormal findings lack specificity [185].

Limitations of current structural imaging techniques appear even more striking subsequent to therapy [184, 191]. Changes in anatomical indicators are slow and may lag behind reduction in the number of viable tumour cells. Indeed, it appears that fibrosis develops as a result of tumour necrosis and initially enlarged tumour sites may remain permanently enlarged after effective sterilization of the tumour. FDG appears particularly useful for the assessment of therapy in patients with lymphomas as changes in the metabolic stage of the tumour appear to reflect more closely viability of the remaining tumour cell mass than tumour volume [189, 192, 193].

Initial staging. FDG imaging in lymphoma was first reported by Paul [183]. He compared FDG with gallium67 using planar imaging in five patients with non-Hodgkin's lymphoma and detected abnormalities in four of the patients with FDG as compared with two of them using gallium.

Okada et al. reported on 21 and then 23 patients with lymphoma of the head and neck regions $[36,187]$. Abnormal PET studies were reported in all patients, while gallium uptake was abnormal in 20 of 21 patients. Low-grade lymphomas appeared to have less FDG uptake than higher grade lymphomas as a good correlation was obtained between FDG uptake and biopsy-obtained estimates of tumour proliferative rate. It has also been suggested that increased FDG uptake is associated with a less favourable prognosis for the lymphoma patient [194].

Leskinen-Kallio et al. [195] also observed that increased FDG uptake was proportional to the histological 


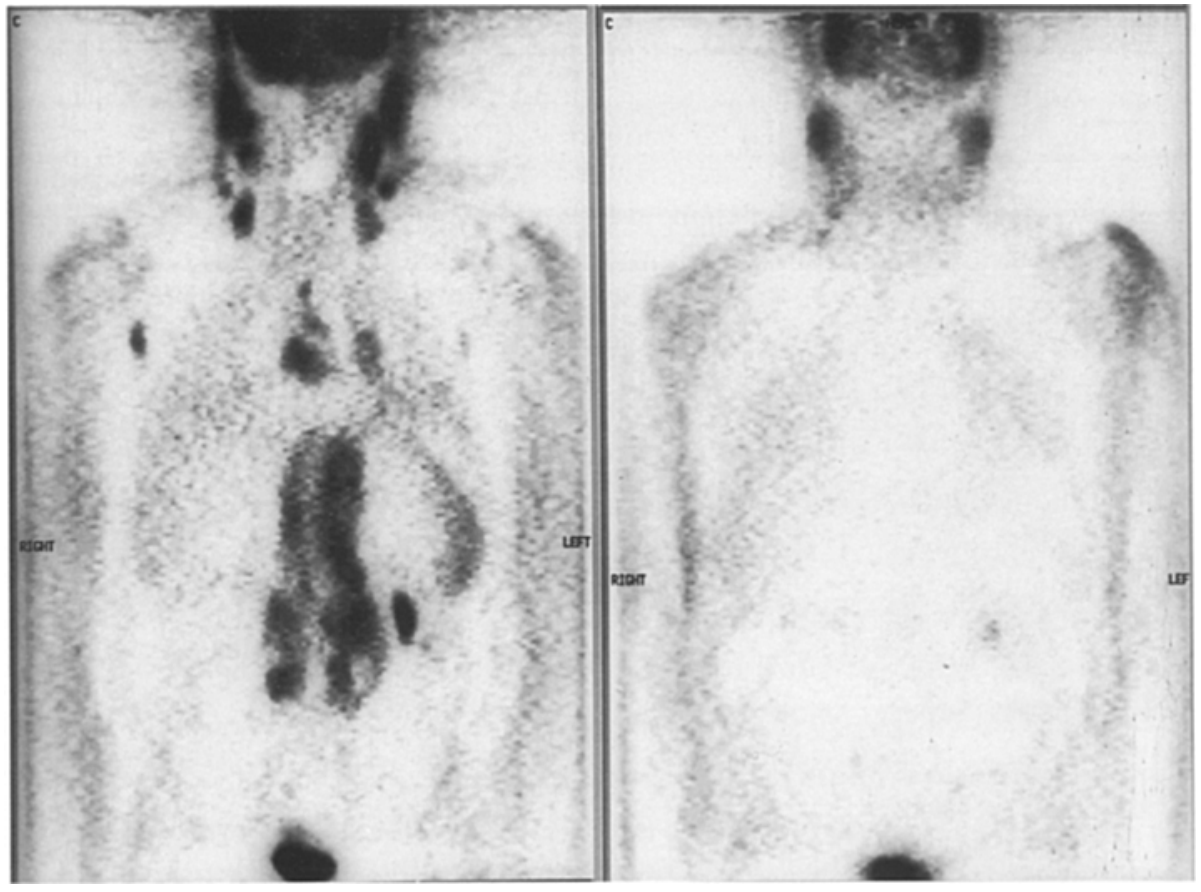

Fig. 4. High-grade non-Hodgkin's lymphoma before (left) and after (right) chemotherapy grade, with the most malignant tumour accumulating the most FDG. Some low-grade tumours were not detected. Based on studies in 14 patients, the authors suggested that ${ }^{11} \mathrm{C}$-methionine might be superior to FDG in detecting lymphomas but that FDG was better at distinguishing tumour grade. Newman et al. [185] compared FDG PET and CT in 16 patients with mixed lymphoma cases. PET (not using the whole-body technique) identified 54 abnormalities in 13 patients compared with 49 by CT. Subsequent studies remained normal in the three patients with normal PET scans. Rodriguez et al. [35] also report on the role of PET in predicting malignancy grade. These limited results suggest the value of FDG for the detection of even low-grade tumours.

Several other abstracts support the effectiveness of FDG PET in lymphomas [193, 196, 197]. PET usually demonstrates more lesions than CT and this may result in patient upstaging (three cases among 26 patients with Hodgkin's disease [198]) and in changes in patient management.

We have studied 42 patients with histologically proven lymphomas [188-200]. Twenty patients had aggressive non-Hodgkin's lymphoma (NHL), 13 low-grade NHL and 9 Hodgkin's disease (HD). Thirty patients were evaluated at initial presentation while 12 underwent PET for disease recurrence. Evaluation of disease extension was performed by PET and compared with clinical evaluation (presence of lymph nodes with a minimal diameter of $10 \mathrm{~mm}$ or more in the cervical, axillary and inguinal regions), with CT (standard size criteria of $1.5 \mathrm{~cm}$ used to define pathology) and with biopsy when available. PET detected more lesions than clinical examination and/or CT in patients with aggressive NHL or HD (9 of 29 patients had more PET sites than clinical sites; 3 of 29 patients had more PET sites than CT sites). Results were different in patients with low-grade NHL: Concordant results were observed in $9 / 14$ patients by clinical examination and in $7 / 13$ patients by CT. More sites were detected by PET than by clinical examination in two patients and more were detected by PET than by CT in one patient, while more sites were detected by clinical examination in three patients and by $\mathrm{CT}$ in five patients. These results differ from other reports concerning low-grade NHL [185, 186]. One possible reason is that other reports have concentrated on a single area for comparison while this study involved whole-body scans. As the uptake in low-grade NHL is lower than in highgrade tumour, the sensitivity of the whole-body technique with limited scanning time may be insufficient to detect all lesions.

Additionally we have found that PET is valuable for the detection of splenic involvement and digestive tract infiltration (three of four cases were detected). By contrast, PET does not appear useful for the detection of bone marrow infiltration as it cannot differentiate bone marrow involvement from non-specific bone marrow stimulation or from growth factor stimulation.

Follow-up of therapy and detection of recurrences and of residual disease. We have also assessed the role of FDG PET imaging in the evaluation of therapy (Fig. 4). Our results concern 55 cases studied for early treatment evaluation (19 patients), end of therapy assessment (18 patients) and detection of recurrences (25 patients). Early response to therapy (two to three chemotherapy cycles) defines a subgroup of patients with good prognosis (eight of nine patients have remained in remission 8 months after the end of therapy) while patients with re- 
sidual FDG uptake have a poor prognosis (four deaths and one case of residual disease among ten patients). FDG PET also appears useful in differentiating scar from residual disease in patients with residual masses and in detecting early recurrences: PET was positive in all cases of clinical recurrence (11 patients) while it detected lesions in three patients with clinical remission [200].

These results need to be confirmed in larger patient groups and with longer follow-up but it already appears that FDG could play an essential role in the follow-up of lymphoma therapy to confirm the therapeutic choice and good prognosis, or, on the contrary, to detect therapeutic resistance at an early stage [201, 202]. Potentially toxic regimens could be stopped early in the latter patients and replaced by an alternative regimen. PET could also be used to select responders for highly toxic or very expensive treatment and enhance both the cost-effectiveness of treatment and the quality of life in these patients.

\section{Head and neck carcinomas}

Head and neck carcinomas are associated with the abuse of alcohol and/or tobacco and their frequency is increasing. They take their origin in the superior alimentary and respiratory tracts and mainly comprise squamous cell carcinoma $(90 \%)$. Other lesions take their origin in glandular tissues (mainly the salivary glands) or in lymph nodes. Head and neck carcinomas have high glycolytic activity and their successful demonstration with FDG was reported in the late 1980 s with the use of a specially collimated gamma camera [202]. Use of ${ }^{11} \mathrm{C}$-methionine has also been proposed in this indication [203, 204].

Initial diagnosis and staging of head and neck carcinomas is based on clinical examination. This is usually quite successful as most tumours are reasonably accessible to observation and palpation by the head and neck specialist. The clinical examination is usually completed by CT or MRI and by biopsy. Palpation has, however, been reported to be superior to structural imaging for lymph node involvement as the latter is strictly based upon the size of the lymph node while palpation assesses the node structure and induration [205].

PET metabolic criteria offer some advantages over anatomical imaging. They can detect superficial or submucosal primary tumour infiltration without adjacent tissue deformation. They can also indicate uptake and involvement of normal size lymph nodes while showing no involvement in some enlarged reactive lymph nodes. Evaluation of the accuracy of FDG PET in the diagnosis of the primary tumour has been performed to validate its potential in this type of tumour rather than to support its clinical use in this indication [206-209]. Minn et al. were able to image $13 / 13$ cancers using FDG [202]. Bailet et al. [210] identified 16/16 primary lesions using PET, including one lesion not well delineated by anatomical imaging (superficial tumour involving the anteri- or tongue). These tumours have a high tumoral to normal metabolism ratio as reported in a concomitant paper from the same group [40, 211]. McGuirt et al. [212] studied 25 patients with laryngeal carcinoma before definitive therapy. PET identified the primary tumour in 22 cases. There were one false-negative and two equivocal lesions, all in the supraglottic region. McGuirt et al. [213] also reported on the identification of benign versus malignant parotid masses. PET identified all 26 lesions and all 12 malignant lesions but made the correct categorization in only $69 \%$ of cases. Indeed, six benign lesions (Warthin's tumours, pleomorphic adenomas and a toxoplasmosis adenopathy) presented falsely positive uptake [214].

In summary, PET is potentially useful in selected indications in patients with primary ENT tumours, for instance to direct the site of biopsy, but cannot be proven cost-effective in this setting.

Definition of lymph node extension in patients with ENT tumour is potentially a more useful indication as lymph node metastases are frequent in the evolution of these cancers and represent the most determinant prognostic factor $[215,216]$. Sixty percent of patients have one or more palpable adenopathies at the time of diagnosis while $40 \%$ have lymph node metastases. The average 5 -year survival is $>50 \%$ in the absence but only around $30 \%$ in the presence of lymph node metastases [217]. Presence or absence of invaded nodes also determines the type of therapy $[218,219]$. In particular, the presence of contralateral disease in a patient eliminates surgery as a treatment option.

Bailet et al. [220] evaluated 203 lymph nodes from eight neck dissection specimens; 17 were positive for malignancy. PET accurately diagnosed $12(71 \%)$ of these positive nodes, as against ten diagnosed by anatomical imaging. PET was false-positive in three reactive nodes. McGuirt et al. [212] correlated the neck nodal status in 27 specimens from 17 patients. PET agreed with pathology in 22 cases $(81 \%)$, with three false-positives and two equivocal specimens. In a separate study, the same authors reported on 49 patients of whom 45 underwent neck dissection, allowing corroboration of clinical and imaging results with histopathological data. PET and CT yielded similar results ( $82 \%$ and $84 \%$ accuracy) and were superior to clinical assessment ( $71 \%$ accuracy) [206].

In our experience in 19 patients with surgical and histopathological verification, PET detected all primary tumours [217]. PET correctly interpreted the absence of metastatic lymph nodes in $11 / 14$ patients but there were three false-positive reactive nodes. PET detected one involved contralateral lymph node in one patient that was not detected by CT or clinical examination. Finally, PET missed two cases of microscopic nodal foci also undetected by $\mathrm{CT}$ and clinical examination.

Definition of residual or recurrent disease after radiotherapy or surgery presents more of a challenge for the clinical examination as well as for anatomical imaging. 


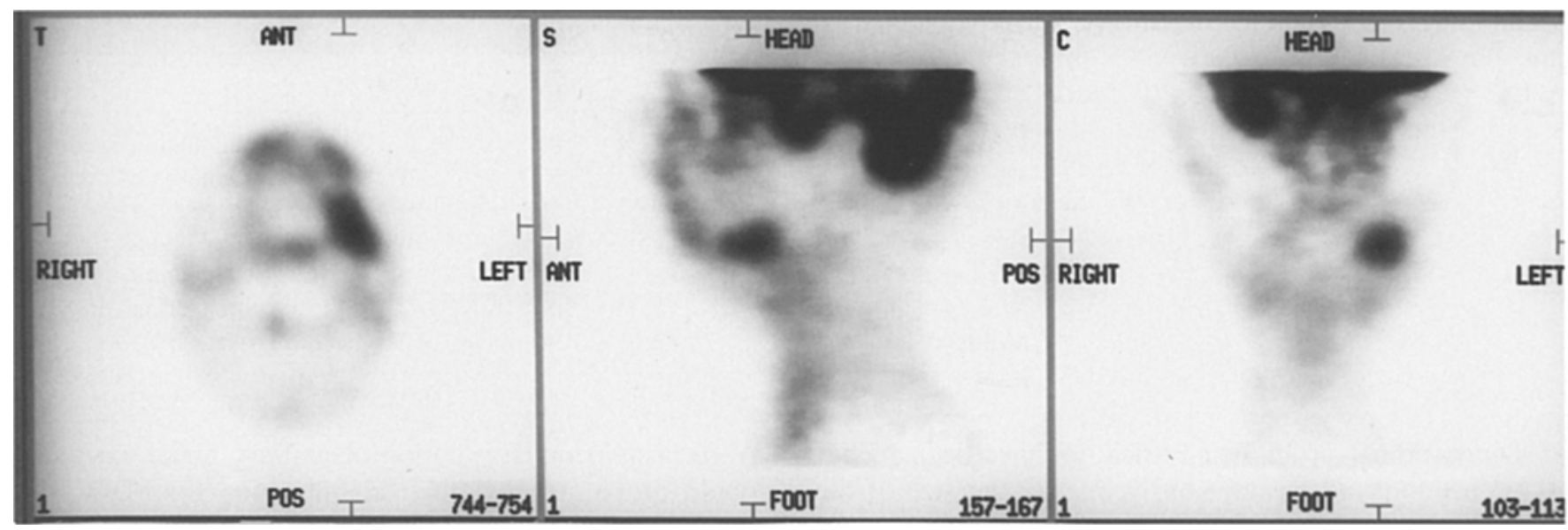

Fig. 5. Local relapse of head and neck carcinoma previously treated by surgery and radiotherapy. CT suggested osteonecrosis of the left jaw. Recurrent disease is evident on PET

The fascial planes can be distorted or destroyed by postsurgical scarring or post-irradiation fibrosis and normal anatomical structures may be unidentifiable. FDG PET appears ideally suited in these indications, as suggested by initial reports [221, 222] (Fig. 5).

Greven et al. [223] reported on 18 patients studied 4 months after radiotherapy. Eleven patients had a normal PET scan at the primary site and none had subsequent recurrence. Seven had abnormal FDG uptake and six of these had biopsy-proven recurrence. Fifteen patients had normal PET at the nodal site and none had recurrences while three patients had abnormal PET with evidence of biopsy-confirmed nodal recurrences in two. Similarly, Bailet et al. [220] compared PET and MRI in ten patients with recurrent tumours 4 months to 4 years after radiotherapy. PET determined recurrence in all patients while MRI was negative or inconclusive and clinical examination was frequently non-specific. A comparative study of FDG SPET and thallium was reported by Mukherji et al. [224].

FDG PET has also been used to monitor tumour response to various chemotherapy or radiotherapeutic regimens. According to Chaiken et al. [225], elevated or rising FDG PET activity after radiation therapy was indicative of persistent or recurrent disease in $89 \%$ of cases (8/9) while a significant decrease in activity was observed in patients in whom local control was achieved. Greven et al. [223, 226], however, did not believe that early PET scan (1 month) accurately reflects the status of disease and recommended a minimum delay of 4 months. These studies extended previous work by Minn et al. [202] and Haberkorn et al. [227], who documented a significant decrement in uptake ratio after irradiation among radioresponsive but not radioresistant tumours. Similarly, tumours appear more sensitive to chemotherapy than lymph nodes [228].

Prognosis. As suggested by Reisser et al. in 50 patients, FDG uptake before therapy can predict prognosis [94, 229]. Patients with an SUV above 3-4 (300\%-400\%) had a less favourable prognosis than patients with a lower SUV value.

\section{Breast cancer}

Breast cancer is the most frequent malignant tumour in women of Western countries [230]. The most frequent form is an adenocarcinoma of the endothelial cells of the galactophorous ducts. It is primarily localized in the external upper quadrant $(50 \%)$, in the internal upper quadrant or in the central regions. Breast cancer is in many cases a systemic disease. Indeed, disease recurrence is metastatic rather than locoregional in nine of every ten cases. Metastases appear early in the course of the disease while the tumour growth rate is slow (doubling time: 1-3 months; a tumour reaches $1 \mathrm{~cm}$ after 5 years and $2 \mathrm{~cm}$ after 10 years) [231-233].

Local extension is along the galactophorous ducts to the nipple and the remaining gland, skin and deep tissues. Breast carcinoma is frequently multicentric (30\%) or bilateral $(7 \%)$. Locoregional extension is via the lymphatic system and carries important prognostic value. Nodal metastasis is found in $60 \%$ of patients at the time of diagnosis and the 5-year recurrence-free survival is $75 \%, 45 \%$ and $20 \%$ with involvement of no, one to three, and more than three axillary nodes, respectively. Mortality is also clearly related to the presence or absence of metastasis [234]. The primary lymph pathway is by contiguity along the external mammary pedicle to the first, second and third axillary groups from the external superior quadrant. The central and internal quadrants also carry lymph to the internal mammary node groups (between the second and third intercostal spaces). From these, extension to the sub- and supraclavicular groups, upper mediastinal groups and contralateral axillary groups is possible. Systemic metastatic extension is haematogenous and primarily affects the axial skeleton, the liver, the lung and the pleura. The brain, ovaries, adrenals and skin are less frequently involved. 
Table 7. Breast carcinoma - nodal extent

\begin{tabular}{lcccll}
\hline Authors & Reference & $\begin{array}{c}\text { No. of } \\
\text { pts. }\end{array}$ & $\begin{array}{l}\text { Sensitivity } \\
(\%)\end{array}$ & $\begin{array}{l}\text { Specificity } \\
(\%)\end{array}$ & Acquisition technique \\
\hline Wahl et al. & 246 & 7 & 100 & - & Attenuation corrected \\
Tse et al. & 243 & 10 & 57 & 100 & Whole-body \\
Adler et al. & 251 & 20 & 90 & 100 & Attenuation corrected \\
Hoh et al. & 83 & 14 & 67 & 100 & Whole-body \\
Avril et al. & 253 & 18 & 72 & 96 & Attenuation corrected \\
Nieweg et al. & 249 & 5 & 100 & - & Attenuation corrected \\
Multicentre & 257 & 49 & 96 & 96 & Various \\
\hline
\end{tabular}

Several other prognostic indicators have been recognized beyond nodal extension: primarily the size of the tumour, the presence or absence of local inflammatory signs, the presence or absence of hormonal receptors [235-237] (progesterone receptors have greater prognostic value than oestrogen receptors) and the age of the patient (women under 35 years have twice the rate of axillary involvement as older women). The histopathological classification based on the degree of differentiation (SBR grades I-III) also carries prognostic information [238], as do more recently developed oncogene-related markers [239].

Diagnosis. Initial therapy is decided upon based on the results of staging and of the prognostic evaluation. The role of PET and in particular of FDG PET in the diagnosis and management of breast carcinoma has been the subject of several studies [240-244]. Several groups have reported a high degree of success in detecting the primary tumour. Although the first feasibility studies included only small numbers of patients with large tumours, larger more representative series have now been reported [245-248]. Using a whole-body imaging technique, Hoh et al. [83] detected $15 / 17$ primary breast carcinomas. Nieweg et al. [249, 250] identified 10/11 primary lesions. Adler et al. [251, 252], in a prospective study, recognized 26/27 malignant lesions. While other studies are forthcoming (some of them are already available in abstract form) that will confirm the high sensitivity of PET for the detection of the primary lesion, it should be noted that most studies have evaluated breast masses of more than $1.0 \mathrm{~cm}$ in diameter and that the sensitivity of the method for definition of small cancers remains to be established $[81,253]$. Also the method's specificity has not been fully determined in a large number of benign lesions. Therefore current results must still be considered preliminary. The need for a new technique in the primary diagnosis of breast tumours must be weighed against the sensitivity and cost of current modalities. There appears to be little space for FDG PET, given the role of mammographic screening and confirmation by needle or surgical biopsies. One potential area of application, however, is in patients with silicone implant augmentation mammoplasties, as reported by Wahl [254]. Use in patients with dense breasts or in patients with unsuccessful needle biopsy has also been suggested.
Nodal extension. Evaluation of axillary nodal extension could prove a more practical indication for FDG PET. Indeed, it could potentially replace axillary lymph node dissection (ALND). ALND is currently performed for its prognostic value only, yet carries significant morbidity and cost $[234,255,256]$. Complications include postoperative seroma formation, arm oedema, breast oedema, nerve injuries and shoulder dysfunction. ALND can significantly prolong hospitalization, anaesthesia and postoperative care or be a separate procedure when associated with breast conservation therapy.

The current incidence of patients with positive node dissection among those receiving partial mastectomies has dropped to $25 \%$ in some reports (probably due to earlier detection). As calculated in an ICP report, a sensitivity and specificity of $90 \%$ and $95 \%$ respectively would have an NPV of $97 \%$ and spare 33 patients the morbidity of ALND at a cost of missing one patient with lymph node involvement [257]. More conservative estimates of sensitivity and specificity ( $75 \%$ and $90 \%$ respectively) would result in an NPV of $92 \%$ and spare 25 patients the morbidity of ALND at the cost of missing two patients with lymph node involvement. As suggested by the authors of the ICP report, even this higher error rate may be justifiable given the limited improvement in survival that would be expected from chemotherapy [257].

Initial results of PET in patients with advanced breast carcinoma demonstrated a high rate of detection of lymph node metastases. Results in subsequent studies have varied from $67 \%$ [83] to $90 \%$ [251] but the number of patients studied remains low and results appear to vary in part with the technique used (sensitivity is potentially higher using an attenuation-corrected static scan than with a whole-body non-attenuated technique) (Table 7). Recent results and our own experience suggest a $75 \%-80 \%$ sensitivity with good specificity $(96 \%)$ [253]. If larger studies in stage I or II breast cancer patients confirm both the sensitivity and the specificity of PET and a low incidence of lymph node metastases $(<30 \%)$ to yield a high NPV ( $>90 \%$ or preferably $>95 \%$ ), PET could replace ALND in these patients. As mentioned earlier, PET also has the potential to detect internal mammary lymph node metastases and this should be a significant advantage in patients with central or internal quadrant tumours. Unfortunately, no data have yet been reported on the clinical impact of this feature. 


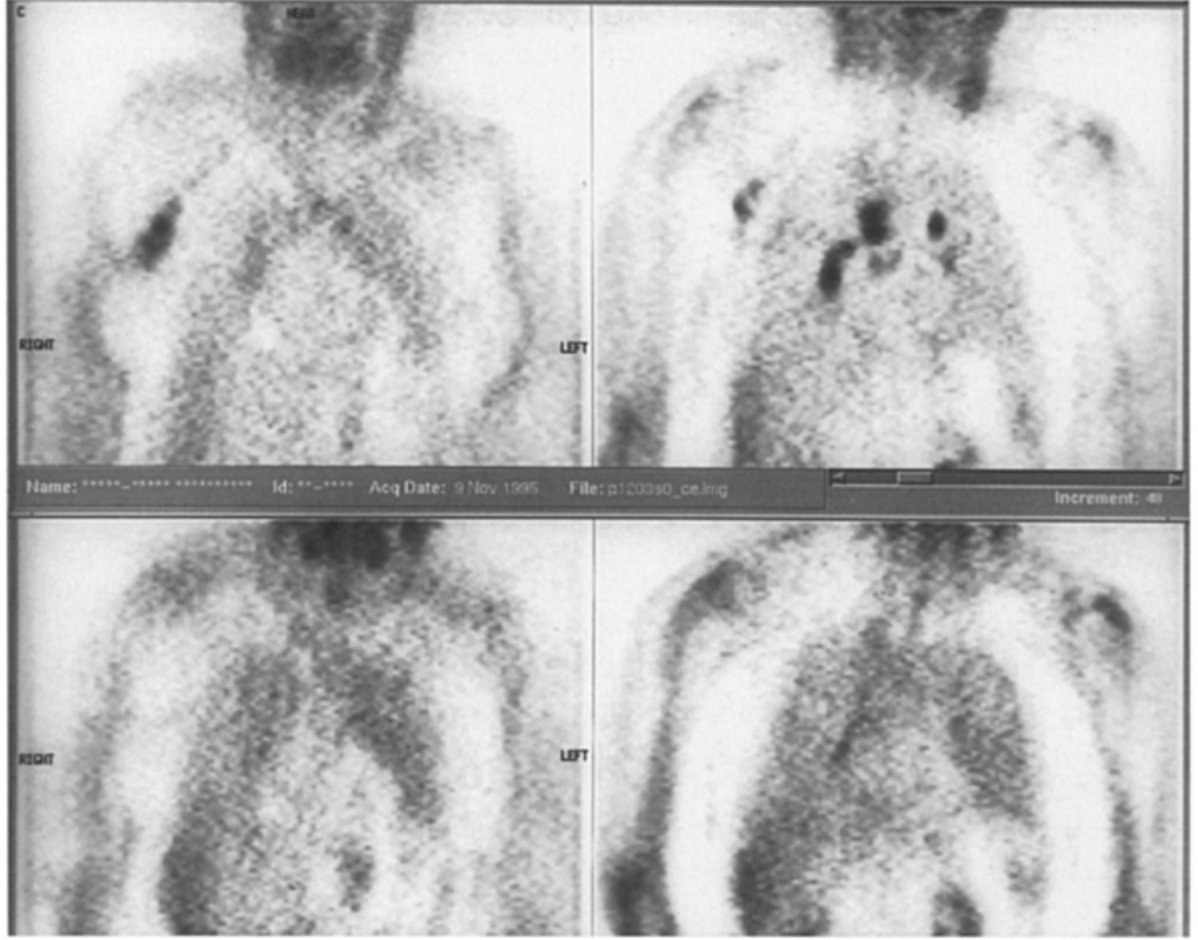

Fig. 6. Hilar mediastinal and right axillary nodal metastases from breast cancer before (superior pannel) and after (inferior pannel) two courses of chemotherapy (Taxotere)
Metastatic staging. PET also has the potential to detect distant metastases, e.g. in the liver, skeleton or more distant nodal chains. Such metastases will radically alter patients' management. In this context the use of wholebody PET could potentially replace the need to perform a conventional metastatic survey including CT, US and conventional skeletal scintigraphy [258]. Available data point to the value of PET in this indication but it has not yet been tested in specific patient groups, such as patients with stage III breast cancer at the time of initial diagnosis, or later on in the disease, e.g. in patients with suspected recurrences [246, 249, 250, 259].

Therapy follow-up. Finally, a number of reports have assessed the role of FDG and PET in assessing response to breast cancer therapy (Fig. 6). Wahl et al. studied 11 women with newly diagnosed primary breast cancer larger than $3 \mathrm{~cm}$ in diameter and undergoing a chemohormonotherapy programme [59]. These patients had one baseline and four follow-up quantitative PET scans to test the feasibility of non-invasive metabolic therapy monitoring. Tumour uptake decreased rapidly in eight patients with partial or complete response while it did not change in non-responders. The metabolic response preceded decrease in tumour size. Furthermore, effective chemotherapy, when repeated, leads to diminution of glucose uptake levels to basal values while FDG uptake increases in patients receiving inefficient therapy. Reports from Nieweg et al. [250], Chaiken et al. [225] and Jansson et al. [260] also suggest a role for PET in the follow-up of therapy.

We have used FDG PET in ten patients considered for bone marrow transplant. Evaluation of the disease extent before chemotherapy and of the initial results after two to three therapy courses has helped us to identify responders, who were submitted to transplant after full therapy, and non-responders, in whom the approach was discontinued to prevent further unnecessary bone marrow toxicity. PET evaluation of early therapy response could also be used to individualize drug selection in difficult cases.

\section{Melanoma}

Melanoma is a cutaneous malignancy whose frequency is increasing. It has a high mortality related to its propensity for early nodal metastasis and hematogenous visceral spread. Between $20 \%$ and $40 \%$ of patients with clinically localized lesions have nodal metastases found at surgery. Although sentinel node biopsy offers promise in the detection of such patients with minimally invasive surgery [261], a technique to non-invasively detect the presence of involved nodes would obviously be of value. Also in treated patients, detection of recurrences or of metastases is made difficult by the wide range of potential hematogenous spread of the tumour. This requires regular chest, abdomen, pelvis and brain CT or MRI, as well as confirmatory procedures in cases of indeterminate or suspicious results [262].

Staging. In animals, melanoma is one of the tumours with the highest glycolytic metabolism and FDG uptake [263]. Initial evaluation confirms the high sensitivity of FDG PET in detecting melanoma lesions. Gritters et al. performed limited area scanning in 12 patients in regions 
of the body having or suspected to contain malignant melanoma on the basis of physical examination and prior imaging data [264]. In superficial lymph nodes, PET correctly identified 7/7 metastastic lymph nodes (including three normal size lymph nodes) and correctly predicted the absence of tumours in 6/6 lymph nodes (accuracy $100 \%$ ). The sensitivity of PET was also very high for intra-abdominal visceral metastases (15/15) ranging in size from 0.5 to $8.0 \mathrm{~cm}$. Five of these lesions were only seen on CT retrospectively or several months later. PET, however, was much less successful in detecting pulmonary metastases (4 of 27 lesions in four patients) but most of the lesions were under $1 \mathrm{~cm}$ in size.

Steinert et al. [265a, 265b] reported on the role of whole-body PET with FDG in staging malignant melanoma in 33 patients. Twenty-three had known metastatic disease while ten had a newly diagnosed melanoma with a high risk of metastases (Breslow thickness $>1.5 \mathrm{~mm}$ ). Of 55 evaluated lesions, 40 proved to be metastatic. PET correctly identified 37 sites but missed three small $(<3 \mathrm{~mm})$ cutaneous metastases. It depicted metastases in six patients and excluded malignancy in ten suspicious sites. Specificity evaluated in ten enlarged benign lymph nodes and three inflammatory lesions was $100 \%$ using marked uptake criteria or $77 \%$ using mild uptake criteria (concomitant sensitivity varied from $73 \%$ to $92 \%$ ). In this study PET detected three of 3 thoracic lymph nodes, albeit with mild intensity only in two cases.

Other studies and abstracts confirm the high sensitivity of FDG PET [266-268]. Kirgan et al. [269] demonstrated more lesions with PET than with CT or MRI in $16 / 24$ patients, with PET leading to a change in management in $45 \%$ of cases; in half of these, surgery was cancelled as more extensive disease was present than previously appreciated. Yao et al. [270] assessed the value of PET in initial staging as compared with other modalities in 31 patients. In 18 of these, PET provided new information and in ten it provided comparable information to all other studies combined, while in three patients it was less effective. The latter cases were brain metastases missed by the whole-body PET acquisition, but in a separate substudy brain acquisition did not miss brain lesions.

Therapy assessment. Strauss et al. [266] studied the effect of chemotherapy on FDG uptake in patients with melanoma. A slight reduction was seen at $90 \mathrm{~min}$ but a greater reduction occurred at $48 \mathrm{~h}$, persisting for 1 week. The degree of FDG uptake reduction correlated directly with the subsequent clinical response.

In conclusion, whole-body PET with FDG appears to contribute importantly in the staging of patients with melanoma. It can detect superficial lymph node or skin lesions down to $0.5 \mathrm{~cm}$ or less and has high sensitivity for visceral metastases with the possible exception of pulmonary lesions. It could serve as a cost-effective onemodality follow-up technique in patients at high risk of recurrence or metastasis. Its role in detecting nodal spread early after initial detection of the melanoma appears promising but will require confirmation in selected patient groups.

\section{Endocrine tumours}

\section{Thyroid}

Diagnosis. Thyroid cancer is uncommon; however, despite its low incidence it presents frequent diagnostic problems due to the prevalence of cold thyroid nodules. Current common diagnostic modalities - clinical examination, thyroid function tests, ultrasonography and thyroid scintigraphy whether with ${ }^{123} \mathrm{I},{ }^{99 \mathrm{~m} \mathrm{Tc}},{ }^{201} \mathrm{Tl}$ or ${ }^{99 \mathrm{~m} T c} \mathrm{~T}-$ sestamibi fail to differentiate benign from malignant nodules and to provide a specific diagnosis. Fineneedle aspiration biopsy, although performed in a large number of patients, has significant limitations related to sampling errors in small tumours. Furthermore, the small size of the collected samples makes it difficult to differentiate a follicular adenoma from a follicular carcinoma. Several authors have suggested a role for FDG PET in this differential diagnosis. Bloom et al. studied 19 patients, 12 with solitary thyroid nodules and seven with multinodular goitres, using a multislice single area non-attenuation-corrected technique [271, 272]. Four of the 12 nodules were malignant while the multinodular goitres were benign. They reported different DURs (dose uptake ratio: a semiquantitative index of FDG uptake parameter) between cancers (three papillary and one follicular) and benign nodules (eight follicular adenomas). One patient with a papillary cancer had another small focus of papillary cancer within the same lobe that was not visualized. Also an incidental papillary cancer $(1 \mathrm{~mm})$ in a patient with a multinodular goitre (independent from the dominant nodule) was not visualized. The authors reported no overlap in DUR values between visualized benign and malignant lesions but the separation was narrow. The uptake in cancer is quite variable and this discrimination is at variance with some other reports. For instance, Joensuu et al. [273] noted FDG accumulation in three patients with a Hürthle cell carcinoma, an anaplastic carcinoma and a thyroid lymphoma but showed only slight or no retention in three papillary carcinomas. Three of eight histopathologically benign tumours also accumulated FDG. In addition, it must be mentioned that FDG uptake is not uncommonly seen in an otherwise normal thyroid for unidentifiable reasons. We therefore believe that the diagnostic application of FDG in patients with undiagnosed solitary thyroid nodules is not currently warranted.

Postoperative staging. Imaging of metastases of thyroid carcinoma with FDG was first performed by Joenssu and Ahonen [274]. They studied three patients with multiple metastases of thyroid carcinoma (one papillary and two 
follicular) using a specially modified gamma camera (1inch crystal and special collimator). Metastases that accumulated only FDG, only iodine or both iodine and FDG could be demonstrated. Metabolic heterogeneity was seen between different metastases in all patients. FDG accumulation may also differ between different metastases of the same patient. The uptake of FDG in metastases was shown to increase in parallel with their progression. They concluded that metastases that accumulate FDG but not ${ }^{131}$ I may behave more aggressively than metastases that accumulate ${ }^{131}$ I but not FDG.

Metabolic heterogeneity was confirmed by Fridrich et al. [275], Scott et al. [276] and Feine et al. [277]. Fridrich studied 12 patients with known thyroid carcinoma and suspected metastases prior to iodine therapy. FDG demonstrated 29 lesions, whereas diagnostic iodine scintigraphy $\left(5 \mathrm{mCi}{ }^{131} \mathrm{I}\right)$ revealed only ten. FDG demonstrated more lesions in nine patients. Post therapy iodine imaging $\left(100 \mathrm{mCi}{ }^{131} \mathrm{I}\right)$ confirmed positive uptake in 20 lesions. Iodine scintigraphy is insufficient to exclude the presence of metastases that may respond to ${ }^{131} \mathrm{I}$ therapy. A positive FDG finding without iodine uptake after ${ }^{131}$ I therapy should lead to another therapeutic strategy.

In 24 patients with differentiated thyroid carcinoma, Feine et al. [277] reported an alternating ("flipflop") pattern of metastases with either ${ }^{131}$ I or FDG uptake. The FDG uptake showed an inverse proportionality to iodine uptake and to tumour differentiation. Grunwald et al. interpreted increased glucose metabolism as a sign of higher malignancy [278].

Sisson et al. [279] reported a patient with a pulmonary metastasis from papillary thyroid carcinoma. This tumour barely concentrated ${ }^{131} \mathrm{I}$ but was well seen using FDG. FDG uptake was lower after $\mathrm{T}_{4}$ therapy and reduction in the TSH level. Sissons et al. suggested the use of FDG uptake measurement as a means to optimize $T_{4}$ treatment level and. TSH suppression in patients with thyroid metastases unlikely to respond to ${ }^{131} \mathrm{I}$, external beam radiation or surgical resection.

Preoperative staging. The annotated bibliography compiled by the Western PET Association suggests preoperative staging as another potential role for PET in patients with thyroid cancer [280]. Indeed, it would be useful to document the presence of metastases prior to surgery for consideration of surgical resection rather than subsequent radioiodine treatment. However, no published report addresses this issue.

\section{Parathyroid}

Conflicting reports are available on the role of FDG PET in localizing abnormal parathyroid tissue. Neumann et al. [281], using attenuation-corrected regional body PET, described correct localization of 17 of 18 parathyroid adenomas and two of four hyperplastic glands in $17 \mathrm{pa}-$ tients. There were three false-positive findings including two follicular adenomas. Sisson and others, however, have reported negative results [282]. They studied seven patients with documented parathyroid adenomas and one with a recurrent hyperplastic gland (weight $0.15-4.5 \mathrm{~g}$ ). Even in retrospect no focus of FDG radioactivity could be found to represent the abnormal parathyroid gland, and this concurs with our experience.

\section{Adrenals}

There are few reports on adrenal imaging with PET. One report has concerned the detection of medullary phaeochromocytoma while another has evaluated the role of PET in differentiating indeterminate adrenal mass in patients with cancer $[121,283]$. No report has as yet dealt with the diagnosis of hyperfunctioning cortical tumours.

Phaeochromocytoma accumulates FDG and can be imaged by the PET method. Shulkin et al. have reported on two patients in whom metaiodobenzylguanidine failed to demonstrate the tumour [283, 284]. FDG PET enabled correct localization of the tumour in both cases with high contrast and should be useful in tumours that do not accumulate MIBG. FDG also accumulates in neuroblastoma [285].

Incidentally discovered adrenal masses are frequent. In patients with cancer, they have a $27 \%-36 \%$ probability of being malignant [286]. Currently, biopsy is required for differential diagnosis despite potential complications, and displays an accuracy of $80 \%-100 \%$ [287]. Boland et al. [121] have evaluated the ability of PET to characterize adrenal masses in patients with cancer. They reported on 24 adrenal masses in 20 patients. PET helped in the correct differentiation of benign from malignant adrenal lesions in all patients. The SUV values ranged from 2.9 to 16.6 in the 14 malignant lesions and from 0.2 to 1.2 in the ten benign lesions. Although a larger sample size is required to confirm these observations, FDG PET appears promising for the evaluation of incidentally identified adrenal masses in patients with cancer.

\section{Neuroendocrine tumours}

Endocrine pancreatic tumours can be visualized by PET. According to Ahlström et al. [288], ${ }^{11} \mathrm{C}-5$-HTP displays higher uptake than does ${ }^{11} \mathrm{C} \mathrm{L}$-dopa in secreting tumours but these amino acid precusors appeared less useful than $\mathrm{CT}$ for the detection of non-functioning tumours. Little experience is available concerning the use of FDG in endocrine pancreatic tumours. In our hands [289], FDG has appeared useful for the detection of carcinoid and neuroendocrine tumours as it demonstrated more lesions than indium-octreotide in six patients studied. The FDG uptake varied markedly from patient to patient, however, possibly reflecting the metabolic activity of the tumour. In a subsequent patient with octreotide-demonstrated gastrinoma, FDG PET was completely normal. 


\section{Pituitary tumours}

Pituitary adenomas have been more frequently studied with " $\mathrm{C}$-methionine or with dopamine $\mathrm{D}_{2}$ receptor binding ligand (for functioning prolactinomas). In the experience of Murh et al. [290] and Bergström et al. [291], all untreated pituitary adenomas studied demonstrated high FDG uptake, similar to or higher than normal brain tissue. The tumour to brain ratio was, however, higher for methionine. Also the variability of FDG uptake in nonsecreting adenomas was higher than that of ${ }^{11} \mathrm{C}-\mathrm{L}$-methionine and the correlation with hormone secretion was less good. Dopamine agonist treatment seemed to reduce FDG uptake as well as methionine uptake. FDG uptake in meningioma was considerably lower than in pituitary adenomas and this feature could be used for differential diagnosis. Although most cases can be effectively diagnosed using more conventional imaging, PET may have a role in selected instances.

\section{Musculoskeletal neoplasms}

Musculoskeletal tumours were among the first non-brain tumours to be imaged by PET. Kern et al. [292] reported on four patients with soft tissue tumours and one with osteogenic sarcoma. As in the brain, a correlation between the grade of the tumour and the extent of FDG uptake was noted in these patients. This observation was confirmed by Adler et al. [37] in five patients with liposarcoma of the thigh. DUR averaged 1.38 in low-grade and 2.45 in high-grade tumours, suggesting a role of FDG in this metabolic distinction. Adler et al. [38] extended this observation in 25 patients presenting six benign lesions and 19 malignant lesions of various grades. High-grade malignancies had DUR values $\geq 1.6$ while lesions with values $<1.6$ were either benign or low grade. In a recent study, Nieweg et al. [293] examined the correlation between tumour grade and FDG metabolic rate (regional glucose metabolic rate and SUV). They studied 18 patients with soft tissue sarcomas and four with benign soft tissue lesions. All sarcomas were clearly visualized, as was one benign lesion. An equivocal scan was obtained in another benign lesion. A correlation was found between glucose metabolism and the histopathological malignancy grade. Such a correlation was not demonstrated for the SUV (calculated as tumour average). Benign lesions could be distinguished from highgrade malignant lesions but not consistently from lesions with low or intermediate malignancy grades.

Preoperative diagnosis and staging. The clinical impact of PET imaging in soft tissue masses was explored by Griffeth et al. [294]. They performed limited axial field of view scanning in 19 patients with ten malignant and ten benign lesions. DUR values provided complete discrimination between benign and malignant lesions. Most patients undergo an extensive evaluation before surgical diagnosis with the goals of evaluation of the nature of the primary lesion, assessment of local invasion and extension, and detection of possible distant metastases. All questionable lesions must be presumed malignant before definitive surgery as there is reluctance to violate tissue planes for simple biopsy. Definitive diagnosis is frequently only made at complete or radical surgical resection to avoid seeding or contamination of adjacent tissue planes with malignant cells.

Current results support the use of PET to help in this preoperative diagnosis even though accuracy cannot be expected to be $100 \%$ and the method of quantification must be better standardized [78]. For those lesions shown to be malignant, PET may also aid in the preoperative planning of biopsy and therapy. Indeed, it provides information regarding the distribution of metabolically active tumour tissue relative to the abundant necrotic, oedematous, inflammatory or postoperative changes in otherwise normal surrounding tissue. PET appears more accurate that CT or MRI in the selection of sites with the greatest concentration of cellular neoplastic elements for histopathological analysis. In this indication PET may be particularly useful in patients with previous surgery, chemotherapy or radiation therapy that has resulted in anatomical changes and distortion of normal planes [295, $296]$. It can predict the benign nature of recurrent masses or allow a conservative biopsy and monitor approach rather than extensive surgical excision of suspicious but potentially benign tissues.

PET also aids in the detection of regional or distant metastases [293]. In the latter study, 12 suspicious lymph nodes (1-2 $\mathrm{cm}$ in diameter) were confirmed as metastatic while four normal size involved lymph nodes were identified. Metastatic mediastinal lymph nodes and an unsuspected primary leiomyosarcoma of the oesophagus were also diagnosed.

PET can be useful to detect the presence of residual or recurrent malignant disease after surgery. In osteogenic sarcoma, detection of pulmonary metastases can also be performed using ${ }^{18} \mathrm{~F}$-fluorine ion to identify an extraosseous site of bone formation or calcification [297].

Finally, Nieweg et al. report on the role of FDG PET in evaluating the results of isolated limb perfusion therapy in a patient with a locally advanced liposarcoma. Before perfusion, a high glucose consumption of the tumour was demonstrated which was absent after perfusion of TNF- $\alpha$, interferon-gamma and melphalan. Subsequent excision confirmed complete necrosis of the tumour [295].

\section{Ovarian carcinoma}

Ovarian carcinoma is the leading cause of death among gynaecological tumours [298]. It has spread throughout the pelvis in about two-thirds of all patients at the time of diagnosis. Non-invasive staging is usually performed using the clinical examination, ultrasonography, urogra- 
Table 8. FDG PET in ovarian cancer [301]

\begin{tabular}{lllllll}
\hline & $\begin{array}{l}53 \text { positive } \\
\text { masses }\end{array}$ & $\begin{array}{l}37 \text { negative } \\
\text { masses }\end{array}$ & $\begin{array}{l}\text { Sensitivity } \\
(\%)\end{array}$ & $\begin{array}{l}\text { Specificity } \\
(\%)\end{array}$ & PPV & NPV \\
\hline PET + & 47 & 3 & 89 & & 94 & 85 \\
PET - & 6 & 34 & 72 & 92 & 64 & 52 \\
CT + & 38 & 21 & 43 & & \\
CT - & 15 & 16 & & & & \\
\hline
\end{tabular}

phy and tomodensitometry. The search for lung and pleural metastases as well as for hepatic metastases is systematic. Confirmation of the disease and definition of its true extent is usually not complete until the time of initial surgery. Therapy after careful evaluation of the lesion consists in maximum early resection followed by chemotherapy and/or radiotherapy. Post-therapy followup is facilitated by monitoring tumoral markers, especially CA 125 (but also CEA and alpha-fetoprotein or $\beta$ HCG in specific tumours, i.e. yolk sac tumours and choriocarcinoma); CA 125, however, is not elevated in all patients with residual or recurrent tumours. Mortality after surgery and radio- or chemotherapy remains high. Indeed, even after negative second-look surgery, recurrences occur in $40 \%-63 \%$ of cases [298]. These recurrences and the mortality primarily result from occult metastases involving the peritoneal surfaces of the pelvis and abdomen and the retroperitoneal lymph nodes. Unfortunately, current diagnostic techniques, including CT or MRI and laparoscopy or culdocentesis, lack sensitivity and specificity for accurate diagnosis and staging of primary and residual or recurrent disease. New methodologies are needed to optimize treatment planning in ovarian carcinoma [153] and FDG PET has been evaluated.

Successful imaging of ovarian cancers with FDG was first reported by Wahl et al. [299]. The largest experience has been reported by Hubner et al. [300]. These authors presented data from an extended series at the ICP meeting [301]. Ninety patients presenting with ovarian masses were studied by limited field or whole-body PET and CT prior to laparotomy for suspected ovarian cancer. High sensitivity and specificity ( $89 \%$ and $92 \%$ ) were reported, with high positive and negative predictive values (94\% and $85 \%$ ). PET identified occult foci of active tumour not apparent on morphological studies (CT sensitivity $72 \%$, specificity $43 \%$ ) (Table 8 ). Data in recurrent disease were available in 44 cases. Again, high sensitivity and specificity were demonstrated (94\% and 100\%).

Other groups have concentrated on patients suspected of recurrent disease. Karlan et al. [302] performed whole-body studies in 12 patients prior to second-look surgery. PET-defined disease in six patients was confirmed by surgery. Six patients with negative scans had no visible disease at surgery; however, in five of these patients microscopic disease was defined by pathology. Casey et al. [303] described 19 patients with suspected recurrent tumour after initial surgical resection (based on clinical signs or biology). The final diagnosis was established by surgery or clinical follow-up. FDG demon- strated 10 of 11 histologically proven tumours, and there was one false-positive result. Sensitivity was $91 \%$ and specificity $88 \%$, versus $55 \%$ and $75 \%$ for CT and $73 \%$ and $100 \%$ for tumour markers. Two patients with metastatic liver lesions were also detected by PET. Results of Avril et al. [304], however, draw attention to the lack of specificity of FDG in patients with pelvic abcesses or inflammatory foci.

PET and FDG appear useful to guide surgery through a more complete staging of abdominal and extra-abdominal tumours, and to avoid second-look surgery, e.g. in cases of extensive dissemination.

\section{Genito-urinary neoplasms}

Few reports have been devoted to the use of FDG PET in patients with genito-urinary neoplasms. The available reports, however, are rather encouraging. Imaging of kidney cancer using FDG has been reported by several groups $[305,306]$. Prolonging the delay between injection and imaging is frequently sufficient to allow adequate contrast for tumour imaging. Wahl et al. [306] have presented results of pilot animal and human studies. They have demonstrated both adenocarcinomas and transitional cell carcinomas, but the place of PET in the diagnosis and staging of these tumours remains to be defined.

Bladder cancer can also be demonstrated using FDG [307]. Visualization of the primary tumour is possible provided the urinary activity has a low concentration. Regional nodal disease can also be demonstrated [308], preferably using iterative reconstruction techniques. Hamey et al. [307] have reported successful detection of distant metastasis.

PET also appears effective for the visualization of testicular carcinoma and in particular germ cell carcinoma [309]. In a study of 21 patients with stage II-IV testicular germ cell tumours, Wilson et al. [310] evaluated various clinical PET indications using a multiwire proportional PET system and FDG. Despite the limited sensitivity and resolution of such a system, they provided convincing arguments for its value in detecting metastatic disease (active disease $>2 \mathrm{~cm}$ in diameter). In patients with malignant teratoma and residual masses after chemotherapy, PET differentiates well-differentiated teratoma, benign lesions and fibrosis from poorly differentiated viable malignant tumours. Surgery of differentiated teratoma remains indicated, however, as relapse is not 
infrequent $(12 \%)$. Determination of the nature of residual masses might be more important in seminoma. Finally, PET and FDG appear useful to follow up the results of therapy. Confirmation in a larger number of patients and using a more quantitative technique is needed.

Results in prostate cancer have been less favourable [311]. Several preliminary reports suggest that PET misses a significant number of primary tumours and nodal metastases [312]. Furthermore, data from Shreeve et al. [131] suggested that close to $50 \%$ of patients with metastatic prostate carcinoma do not have their bone lesions visualized by FDG PET.

\section{Brain tumours}

Most PET studies performed for the evaluation of brain tumours concern gliomas, the most frequent type of primitive brain tumours. According to the W.H.O. classification, gliomas include four malignancy grades corresponding to different therapeutic indications and prognosis.

Differential diagnosis. When lesions are demonstrated by CT or MRI with contrast enhancement and peripheral oedema, differential diagnosis usually has to be made between a tumour and an abscess: PET shows high FDG uptake in tumoral lesions (especially high-grade lesions) [11,33, 314], and no or low uptake of FDG in abscesses; however, in some cases, tumours, even high-grade gliomas, may exhibit low FDG uptake, whereas some abscesses may exhibit high uptake of FDG [315] or ${ }^{11} \mathrm{C}$ methionine (MET) [316]. In patients with AIDS, FDG PET has proved useful to differentiate between brain lymphoma and non-malignant lesions such as toxoplasmosis or syphilis [317].

Dethy et al. studied the use of PET with FDG or MET in patients with chronic brain haematomas [318], and observed moderate uptake of both tracers in examinations performed 20-32 days after the initial symptoms. PET was not helpful at that time in differentiating between neoplastic and non-neoplastic origins of an intracerebral haematoma. However, the uptake of both tracers decreased 76-103 days after the initial symptoms, and PET might then be useful in detecting a tumour underlying the haematoma.

When CT or MRI shows a non-enhancing lesion, the differential diagnosis must usually be made between a low-grade glioma and a non-tumoral lesion such as gliosis, post-traumatic scar tissue, or even sometimes an ischaemic lesion. While in some cases of low-grade gliomas PET may show increased FDG uptake, in most cases FDG uptake is decreased [11, 33, 314], as in nontumoral lesions. In these cases, MET is very helpful, as the uptake of MET is increased in nearly all low-grade gliomas as well as in high-grade gliomas [319-323]. PET is, however, unsuccessful in differentiating between the various histological types of brain tumours, as high uptake of FDG is seen not only in gliomas but also in lymphomas [317, 324, 325], meningiomas [326], pituitary adenomas [327] and metastases [328].

In difficult cases, PET, performed in stereotactic conditions if necessary, can help to select the best site to perform a biopsy [329-334]. Levivier et al. [331] showed that the number of non-diagnostic trajectories of stereotactic biopsies was smaller if the target was defined by PET and CT rather than by CT alone. In lowgrade lesions, where FDG uptake is usually low, MET or ${ }^{11} \mathrm{C}$-tyrosine may be useful in detecting the best site for biopsy.

Preoperative staging. Primitive brain tumours are usually unifocal and do not metastasize. Staging therefore mainly concerns prediction of the grade of malignancy, delineation of the tumour, and determination of tumour heterogeneity.

Since the initial description of the use of FDG PET in cerebral gliomas by Di Chiro et al. [33], a lot of studies have been performed, and have drawn the same conclusions: There is a clear correlation between the uptake of FDG and the histological grade of gliomas, and also between the uptake of FDG and the survival prognosis [11, $314,335-337]$. The usual visual pattern is a hot spot in high-grade lesions, and a cold spot in low-grade gliomas; however, a cold spot may be seen in some highgrade gliomas; on the other hand, the presence of a hot spot in a low-grade glioma is usually an indicator of malignant degeneration [338]. The same correlations are found when the ratio between tumour and the normal contralateral cortex (T/CTX ratio) is considered. Patronas et al. [339] postulated that within high-grade gliomas, the uptake of FDG might be a more important prognostic factor than the histological grade, but most of the cases included in this study were already recurrences.

The absolute values of glucose consumption are also correlated with the histological grade of gliomas, but there is some overlap between the grades, and most authors consider that, for clinical use, these calculations do not yield more information than visual analysis combined with a semi-quantitative evaluation of the T/CTX ratio. Moreover, the principle of quantitative glucose consumption calculation is controversial in brain tumours [11, 340-342], and results can be modified by some medications such as corticosteroids [343] or barbiturates [344]. Patients usually fast for 4-6 $\mathrm{h}$ before the PET examination, but Ishizu et al. [345] have calculated that glucose loading decreases FDG uptake in the normal cortex more than in the tumour, resulting in an increased T/CTX ratio by $26 \%$. In a study concerning grade II and III gliomas, Herholtz et al. [346] found a clear correlation between the uptake of FDG and the tumour cell density evaluated by multiple stereotactic biopsies.

One exception to the correlation between FDG uptake and malignancy is the juvenile pilocytic astrocytoma, a very benign lesion. Fulham et al. [347] found a high up- 
take of FDG in these lesions, higher than in other lowgrade astrocytomas and equivalent to that in anaplastic astrocytomas. It is also known that these lesions usually exhibit contrast enhancement on CT or MRI. These "pseudo-malignant" features of a typically benign lesion are interpreted to reflect the unusual vascularity of pilocytic astrocytomas, while the increased glucose utilization rate might be related to expression of the glucose transporter.

FDG PET can also show remote metabolic effects based on deafferentation by the lesion. A depressed cerebellar glucose metabolism (cerebellar diaschisis) contralateral to brain tumours (or other lesions) usually occurs when they invade the motor cortex or the thalamus [348].

Methionine studies in brain gliomas have also shown a correlation between the uptake of this tracer and the histological grade, but to our knowledge no correlation has been reported between the uptake of MET and prognosis [320, 322, 349-352]. Few studies have compared FDG and MET; they have demonstrated that FDG is probably better for establishing the degree of malignancy, whereas MET better delineates the lesions, especially low-grade gliomas [319, 321, 323, 353, 354].

In meningiomas, Di Chiro et al. [326] found a correlation between the tumoral glucose utilization, the malignancy and the probability of recurrence. There was also a significant inverse correlation between the glucose metabolic rate and the doubling time. The strong correlation between FDG uptake and the clinical outcome led Di Chiro et al. to conclude that the metabolic rate is at least as important as the histological classification in these tumours. Borbely et al. [355] performed FDG PET in five patients with cranial or spinal neuromas, and found a higher uptake of FDG in the case where the tumour recurred than in the other cases where the lesion was stable over time.

Postoperative evaluation of residual tumour. CT and MRI cannot reliably differentiate the presence of residual tumour from postoperative enhancement. Glantz et al. [356] have studied tumour patients after surgery, compared them with patients operated on for epilepsy, and compared gliomas before and after corticosteroid therapy: they found that FDG uptake is not increased in the postoperative period (in epilepsy surgery or total tumour resection), is not affected by corticosteroid therapy, and accurately predicts the persistence of tumoral tissue, and thus early recurrence.

Follow-up of therapy. In rats, Ito et al. [357] showed a $15 \%$ decrease in glucose uptake by the normal brain 4 days to 4 weeks after radiotherapy. In experimental rat brain tumours, the uptake of FDG [358] and MET [359] by the tumour decreased early after irradiation, except in radioresistant tumours.

In humans, Mineura et al. [360] reported a paediatric case where a $50 \%$ decrease of FDG uptake after irradia- tion was highly consistent with the period of clinical relief. After a combination of radio- and chemotherapy, Ogawa et al. [361] measured a mean reduction of glucose consumption of $41 \%$ in tumours, and of $14 \%$ in normal brain tissue. Rozental et al. found that the tumour to white matter ratio increased $20 \%-100 \% 24 \mathrm{~h}$ after chemotherapy [362], and then decreased to between $22 \%$ above and $35 \%$ below baseline 28 days later. Hölzer et al. [363] found no differences between FDG PET before and 6 and 12 months after radiochemotherapy in 15 glioblastomas. However, to our knowledge, no correlation has been demonstrated between prognosis and an early PET modification after treatment.

In posterior fossa tumours and primitive neuroectodermal tumours, Holthoff et al. [364] found a good correlation between the modifications of FDG uptake before and after treatment and the neuroradiological findings. FDG PET also corresponded to the duration of initial clinical improvement.

Differential diagnosis between tumour recurrence and radiation necrosis. It is most often impossible to make this differential diagnosis by CT or MRI in those patients who have been operated on and then treated by radiotherapy, and present a few months later with a partially necrotic lesion and peripheral contrast enhancement. FDG PET proved useful in these cases to differentiate tumour recurrences exhibiting a high uptake of FDG from radiation necrosis in which the uptake of FDG is low [356, 365-367]. In this indication, FDG PET proved superior to rubidium-82 PET [367]. Some false-negative FDG cases have been demonstrated, however, especially in recurrences of low-grade gliomas but also in histologically proven recurrences of high-grade gliomas. Some false-positive cases have also been demonstrated [361, 368-371]. Falsenegative cases may especially correspond to small lesions included in the cortex, or to partially cystic or necrotic lesions. The usefulness of FDG PET in the differential diagnosis between recurrence and radiation necrosis has also been demonstrated after interstitial brachytherapy or radiosurgery for metastases [368, 372].

In recurrences of proven high-grade gliomas, Patronas et al. [339] identified all the tumours, and demonstrated a correlation between the FDG uptake (ratio of the tumour to the corresponding contralateral brain) and the median survival time: 19 months if the ratio was equal to or less than 1.4 , compared to 5 months if the ratio was greater than 1.4. They also suggested that FDG PET in these cases could be a more important prognostic factor than histology, as the survival of patients with grade IV gliomas with a low FDG uptake was better than that of patients with grade III gliomas with a high FDG uptake. These conclusions were later confirmed by Alavi et al. [93], who observed a median survival of 7 months for the hypermetabolic tumours, compared to 33 months for the hypometabolic lesions.

In a few studies performed with MET, this tracer also proved useful in detecting biologically active residual or 
recurrent brain tumours, and could yield less false-negative results than FDG PET [369, 373, 374]. In our experience, MET proved much better than FDG in delineating tumour recurrences, and usually clearly depicted low-grade lesions and some high-grade lesions that were not seen with FDG [354].

\section{How to improve clinical PET}

The use of 3D-imaging techniques and of large field of view detectors has considerably increased system sensitivity and reduced statistical noise, thereby improving clinical PET.

Reduction in image artefacts can be obtained through transmission correction, iterative reconstruction and better patient preparation. Attenuation correction, up to now impractical for whole-body imaging (due to the excessive duration of transmission acquisition), will become possible with the use of a single-photon emitter $\left({ }^{137} \mathrm{Cs}\right)$. Furthermore, the use of transmission image segmentation has been shown to decrease statistical noise and improve the quality of image reconstruction. Maximum likelihood iterative reconstruction also decreases artefacts, especially in areas of high heterogeneous count activity, and can facilitate image interpretation. Improved speed of computing and better algorithms make these easier to use in clinical practice. Finally, better patient preparation, adequate fasting, glucose level verification, adequate relaxation or use of diazepam as a muscle relaxant and use of forced diuresis for pelvic examination (furosemide) can also contribute to the quality of the examination.

Interpretation can also be improved by anatomical correlation, in particular through the use of image fusion with structural images. Accurate quantification could also significantly contribute to interpretation. Most important, however, is patient selection. As FDG is a nonspecific tracer, its accuracy depends on proper patient selection. Inclusion of patients with low disease probability increases the likelihood of false-positives, and the technique is not suited to unselected screening. However, in adequately selected groups with proper diagnosis verification, the technique has been shown to have a considerable impact.

\section{References}

1. Phelps ME, Mazziotta J, Schelbert HR. Positron emission tomography and autoradiography. New York: Raven Press, 1986.

2. Wagner HN Jr. Nuclear medicine; what it is and what it does. In: Wagner HN Jr, Szabo Z, Buchanan JW, eds. Principles of nuclear medicine. New York: Williams-Saunders; 1995: 1-8.

3. Phelps ME, Huang SC, Hoffman EJ et al. Tomographic measurement of local cerebral glucose metabolic rate in humans with (F-18)2-fluoro-2-deoxy-D-glucose: validation of method. Ann Neurol 1979; 6: 371-388.
4. Reivich M, Kuhl DE, Wolf A et al. The ( $\left.{ }^{18} \mathrm{~F}\right)$-fluorodeoxyglucose method for the measurement of local cerebral glucose utilization in man. Circ Res 1979; 44: 127-137.

5. Wagner HN Jr. Clinical PET: its time has come. I Nucl Med 1991; 32: 561-564.

6. Wahl RL. Positron emission tomography: application in oncology. In: Murray ICP, EIl PJ, eds. Nuclear medicine in clinical diagnosis and treatment. London: Churchill Livingstone; 1995: 801-820.

7. Strauss LG, Conti PS. The applications of PET in clinical oncology. J Nucl Med 1991; 32: 623-648.

8. Reske SN, Bares R, Bull U et al. Klinkische Wertigkeit der Positronen-Emissions-Tomographie (PET) bei onkologischen Fragestellungen: Ergebnisse einer interdisziplinären $\mathrm{Ko}-$ nsensuskonferenz (clinical value of positron emission tomography in oncology: results of an interdisciplinary consensus conference). Nucl Med 1996; 35: 42-52.

9. Warburg O, Wind F, Neglers E. On the metabolism of tumors in the body. In: Warburg O, ed. Metabolism of tumors. London: Constable; 1930: 254-270.

10. Som P, Atkins HL, Bandoypadhyay D, et al. A fluorinated glucose analog, 2-fluoro-2-deoxy-D-glucose (F-18): nontoxic tracer for rapid tumor detection. J Nucl Med 1980; 21: 670-675.

11. Di Chiro G. Positron emission tomography using ${ }^{18}$ F-fluorodeoxyglucose in brain tumors. A powerful diagnostic and prognostic tool. Invest Radiol 1986; 22: 360-371.

12. Warburg O. The metabolism of tumors. New York: Smith RR; 1931: 129-169.

13. Warburg O. On the origin of cancer cells. Science 1956; 123 : 309-314.

14. Hatanaka M. Transport of sugar in tumor cell membranes. Biochem Biophys Acta 1974; 355: 77-104.

15. Hiraki Y, Rosen OM, Birnbaum MJ. Growth factors rapidly induce expression of the glucose transporter gene. $J$ Biol Chem 1988; 27: 13655-13 662.

16. Hiraki Y, De Herreros AG, Birnbaum MJ. Transformation stimulates glucose transporter gene expression in the absence of proteine kinase C. Proc Natl Acad Sci USA 1989; 86: 8252-8256.

17. Murakami T, Niushiyama T, Shirotani $\mathrm{T}$ et al. Identification of two enhancer elements in the gene encoding from the mouse which are responsive to serum, growth factor and oncogenes. J Biol Chem 1992; 267: 9300-9306.

18. Shawver LK, Olson SA, White MK, Weber MH. Degradation and biosynthesis of the glucose transporter protein in chicken embryo fibroblasts transformed by the src oncogene. Mol Cell Biol 1987; 7: 2112-2118.

19. Birnbaum MJ, Haspel HC, Rosen OM. Transformation of rat fibroblasts by FSV rapidly increases glucose transporter gene transcription. Science 1987; 235: 1495-1498.

20. Slater DW, Baldwin SA, Lienhard GE, Weber MJ. Proteins antigenically related to the human erythrocyte glucose transporter in normal and Rous sarcoma virus-transformed chicken embryo fibroblasts. Proc Natl Acad Sci USA 1982; 79: 1540-1544.

21. Godwin AK, Lieberman MW. Early and late responses to induction of ras T24 expression in Rat-1 cells. Oncogene 1990; 5: $1231-1241$

22. Godwin AK, Lieberman MW. Elevation of glucose transporter, C-myc and transin ARN levels by Ha-rasT24 is independent of its effect on the cell cycle. Mol Carcinogen 1991; 4: 275-285. 
23. Sistonen L, Holtta E, Makela TP et al. The cellular response to induction of the $\mathrm{P} 2 \mathrm{lc}-\mathrm{Ha}$-ras oncoprotein includes stimulation of jun gene expression. EMBO J 1989; 9: 815-821.

24. Flier JS, Mueckler MM, Usher P, Lodish HF. Elevated levels of glucose transport and transporter messenger RNA are induced by ras and sarc oncogenes. Science 1987; 235: 1492-1495.

25. Hartung T, Büchler M, Grimmel $\mathrm{S}$ et al. Correlation of increased FDG-uptake and elevated expression of glucose transporter 1 gene in human pancreatic carcinoma. Eur J Nucl Med 1994; 21 : S17.

26. Yamamoto T, Seino Y, Fukumoto $H$ et al. Overexpression of facilitated glucose transporter genes in human cancer. Biochem Biophys Res Commun 1990; 170: 223-230.

27. Nishioka T, Oda Y, Seino Y et al. Distribution of the glucose transporters in human brain tumors. Cancer Res 1992; 52: 3972-3979.

28. Su TS, Tsai TF, Chi CW et al. Elevation of facilitated glucose transporter messenger RNA in human hepatocellular carcinoma. Hepatology 1990; 11: 118-122.

29. Monakhov NK, Neistadt EL, Shavlovskii MM et al. Physicochemical properties and isoenzyme composition of hexokinase for normal and malignant human tissues. I Natl Cancer Inst 1978; 61: 27-34.

30. Parry DM, Pederson PL. Intracellular localization and properties of particulate hexokinase in the Novikoff ascites tumor: evidence for an outer mitochondrial membrane location. J Biol Chem 1983; 258: 10 904-10 912.

31. Gallagher BM, Fowler JS, Gutterson NI et al. Metabolic trapping as a principle of radiopharmaceutical design: some factors responsible for the biodistribution of F-18-2-deoxy-2-fluoro-D-glucose. J Nucl Med 1989; 19: 1154-1161.

32. Sokoloff L, Reivich M, Kennedy $\mathrm{C}$ et al. The $\left({ }^{14} \mathrm{C}\right)$-deoxyglucose method for the measurement of local cerebral glucose utilization: theory, procedure and normal values on the conscious and anesthetized albino rat. $J$ Neurochem 1977; 28 : 897-916.

33. Di Chiro G, De La Paz RL, Brooks RA et al. Glucose utilization of cerebral gliomas measured by $\left({ }^{18} \mathrm{~F}\right)$ fluorodeoxyglucose and positron emission tomography. Neurology 1982; 32: $1323-1329$.

34. Okazumi S, Isono K, Enomoto $\mathrm{K}$ et al. Evaluation of liver tumors using ${ }^{18} \mathrm{~F}$-fluorodeoxyglucose PET: characterization of the tumor and assessment of the effect of the treatment. $J \mathrm{NuCl}$ Med 1992; 33: 333-339.

35. Rodriguez M, Rehn S, Ahlstrom $\mathrm{H}$ et al. Predicting malignancy grade with PET in non-Hodgkin's lymphoma. $J$ Nucl Med 1995; 36: 1790-1796.

36. Okada J, Yoshikawa K, Itami $M$ et al. Positron emission tomography using fluorine-18-fluorodeoxyglucose in malignant lymphoma: a comparison with proliferative activity. $J \mathrm{NuCl}$ Med 1992; 33: 325-329.

37. Adler LP, Blair HF, Williams RP et al. Grading liposarcomas with PET using ${ }^{18}$ F-FDG. $J$ Comput Assist Tomogr 1990; 14: 960-962.

38. Adler LP, Blair HF, Makley JT et al. Noninvasive grading of muskuloskeletal tumors using PET. J NuCl Med 1991; 32: $1508-1512$.

39. Sweeney MJ, Ashmore J, Morris HP, Klemi A. Comparative biochemistry of hepatomas. IV. Isotopes studies of glucose and fructose metabolism in liver tumors of different growth rates. Cancer Res 1963; 25: 995-1002.

40. Haberkorn U, Strauss LG, Reisser C et al. Glucose uptake, perfusion, and cell proliferation in head and neck tumors: rela- tion of positron emission tomography to flow cytometry. $J$ Nucl Med 1991; 32: 1548-1555.

41. Higashi K, Clavo AC, Wahl RL. Does FDG uptake measure prolifetrative activity of human cancer cells? In vitro comparison with DNA flow cytometry and tritiated thymidine uptake. $J$ Nucl Med 1993; 34: 414-419.

42. Kubota R, Yamada S, Kubota K et al. Intratumoral distribution of flurorine-18-fluorodeoxyglucose in vivo: high accumulation in macrophages and granulation tissues studied by microautoradiographic comparison with FDG. J Nucl Med 1992; 33: 1972-1980.

43. Minn $\mathrm{H}$, Joensuu $\mathrm{H}$, Ahonen A et al. Fluorodeoxyglucose imaging: a method to assess the proliferative activity of human cancer in vivo. Comparison with DNA flow cytometry in head and neck tumors. Cancer 1988; 61: 1776-1781.

44. Minn $\mathrm{H}$, Clavo AC, Grenman $\mathrm{R}$ et al. In vitro comparison of cell proliferation kinetics and uptake of tritiated fluorodeoxyglucose and L-methionine in squamous-cell carcinoma of the head and neck. J Nucl Med 1995; 36: 252-258.

45. Minn H, Leskinen-Kallio S, Lindholm P et al. ${ }^{18} \mathrm{~F}$-fluorodeoxyglucose uptake in tumors: kinetic vs. steady-state methods with reference to plasma insulin. $J$ Comput Assist Tomog 1993; 17: 115-123.

46. Wahl RL, Clavo AC. Effects of hypoxia on cultured human tumor cell uptake of thymidine, L-methionine and FDG. $J$ Nucl Med 1993; 34: 73P.

47. Lindholm P, Minn H, Leskinen-Kallio S, Bergman J. Influence of the blood glucose concentration on FDG uptake in cancer. A PET study. J Nucl Med 1993; 34: 1-6.

48. Yao WJ, Hoh CK, Hawkins RA et al. Quantitative PET imaging of bone marrow glucose metabolic response to hematopoietic cytokines. J Nucl Med 1995; 36: 794-799.

49. Wahl RL, Quint LE, Greenough RL et al. Staging of mediastinal non-small cell lung cancer with FDG-PET, CT and fusion images: preliminary prospective evaluation. Radiology 1994; 191: 371-377.

50. Kubota K, Ishiwata K, Kubota $R$ et al. Tracer feasibility for monitoring tumor radiotherapy: a quadruple tracer study with fluorine-18-fluorodeoxyglucose or fluorine-18-fluorodeoxyuridine, $\mathrm{L}$-(methyl-14 $\mathrm{C}$ )methionine, $(6-3 \mathrm{H})$ thymidine, and gallium-67. J Nucl Med 1991; 32: 2118-2123.

51. Kubota R, Kubota K, Yamada S et al. Methionine uptake by tumor tissue: a microautoradiographic comparison with FDG. J Nucl Med 1995; 36: 484-492.

52. Ishiwata $\mathrm{K}$, Ido $\mathrm{T}$, Honda $\mathrm{C}$ et al. 4-Borono-2-(18F)fluoro-D,Lphenylalanine: a possible tracer for melanoma diagnosis with PET. Int J Radiat Appl Instrum 1992; 19: 311-318.

53. Ishiwata $\mathrm{K}$, Vaalburg W, Elsinga $\mathrm{PH}$ et al. Metabolic studies with $\mathrm{L}-\left(1-{ }^{14} \mathrm{C}\right)$ tyrosine for the investigation of a kinetic model to measure protein synthesis rates with PET. $\mathrm{J} \mathrm{Nucl} \mathrm{Med}$ 1988; 29: 524-529.

54. Larson SM, Grunbaum Z, Rasey J. Positron imaging feasibility studies: selective tumor concentration of ${ }^{3} \mathrm{H}$-thymidine, ${ }^{3} \mathrm{H}$-uridine, and ${ }^{14} \mathrm{C}$-2-deoxyglucose, Radiology 1980; 134: 771-773.

55. Shields AT, Mankoff D, Graham MM et al. Analysis of 2-carbon-11-thymidine blood metabolites in PET imaging. $J \mathrm{Nucl}$ Med 1996; 37: 290-296.

56. Willemsen ATM, Vanwaarde A, Paans AMJ et al. In vivo protein synthesis rate determination in primary or recurrent brain tumors using L-[1-C-11]thyrosine and PET. J Nucl Med 1995; 36: $411-419$.

57. DeGrado TR, Turkington TG, Williams JJ et al. Performance characteristics of a whole-body PET scanner. $J$ Nucl Med 1994; 35: 1398-1406. 
58. Wienhard K, Dahlbom M, Eriksson L et al. The ECAT EXACT high resolution 1 performance of a new high resolution positron scanner. J Comput Assist Tomogr 1994; 18: 110-118.

59. Karp JS, Muehllehner G, Mankoff DA et al. Continuous-slice PENN-PET: a positron tomograph with volume imaging capability. $J$ Nucl Med 1990; 31: 617-627.

60. Macfarlane DJ, Cotton L, Ackermann RJ et al. Triple-head SPECT with 2-[fluorine-18]fluoro-2-deoxy-D-glucose (FDG): initial evaluation in oncology and comparison with FDG PET. Radiology 1995; 194: 425-429.

61. Glass EC, Nelleman P, Hines H et al. Initial coincidence imaging experience with a SPECT/PET dual head camera. $J \mathrm{NuCl}$ Med 1996; 37: 53P

62. Glaspy JA, Hawkins R, Hoh CK, Phelps ME. Use of positron emission tomography in oncology. Oncology 1993; 7: 41-50.

63. Karp JS, Muehilehner G, He Qu et al. Singles transmission in volume imaging $\mathrm{PET}$ with a ${ }^{137} \mathrm{Cs}$ source. Phys Med Biol 1995; 40: 929-944.

64. Lowe VJ, DeLong DM, Hoffman JM et al. Optimum scanning protocol for FDG-PET evaluation of pulmonary malignancy. $J$ Nucl Med 1995; 36: 883-887.

65. Yu JN, Fahey FH, Harkness BA et al. Evaluation of emissiontransmission registration in thoracic PET. J Nucl Med 1994; 35: 1777-1780.

66. Yu JN, Fahey FH, Gage HD et al. Intermodality, retrospective image registration in the thorax. J Nucl Med 1995; 36: 2333-2338.

67. Wu HM, Huang SC, Choi Y et al. A modeling method to improve quantitation of fluorodeoxyglucose uptake in heterogeneous tumor tissue. J Nucl Med 1995; 36: 297-306.

68. Hooper PK, Meikle SR, Eberl S, Fulham MT. Validation of postinjection transmission measurements for attenuation correction in neurological FDG-PET studies. $\mathrm{J} \mathrm{Nucl} \mathrm{Med} \mathrm{1996;}$ 37: $128-136$.

69. Smith RJ, Karp JS. Attenuation correction in whole-body PET using short transmission scans. I Nucl Med 1996; 37: 172P.

70. Lowe VJ, Hoffman JM, DeLong DM et al. Semiquantitative and visual analysis of FDG-PET images in pulmonary abnormalities. J Nucl Med 1994; 35: 1771-1776.

71. Patlak CS, Blasberg RG. Graphical evaluation of blood-tobrain transfer constants from multiple-time uptake data. Generalizations. J Cereb Blood Flow Metab 1985; 5: 584-590.

72. Zasadny KR, Wahl RL. Standardized uptake values of normal tissues at PET with 2-(fluorine-18)-fluoro-2-deoxy-D-glucose: variations with body weight and a method for correction. $R a$ diology 1993; 189: 847-850.

73. Fischman AJ, Alpert NM. FDG-PET in oncology: there's more to it than looking at pictures. J Nucl Med 1993; 34: $6-11$.

74. Minn H, Zasadny KR, Quint LE et al. Lung cancer: reproducibility of quantitative measurements for evaluating 2-[F-18]fluoro-2-deoxy-D-glucose uptake at PET. Radiology 1995; 196: 167-173.

75. Gatenby RA. Potential role of FDG-PET imaging in understanding tumor-host interaction. J Nucl Med 1995; 36: 893-899.

76. Lindholm P, Leskinen-Kallio S, Kirvela $\mathrm{O}$ et al. Head and neck cancer: effect of food ingestion on uptake of C-11 methionine. Radiology 1994; 193: 863-867.

77. Minn H, Nuutila $P$, Lindholm $P$ et al. In vivo effect of insulin on tumor and skeletal muscle glucose metabolism in patients with lymphoma. Cancer 1994; 73: 1490-1498.
78. Keyes JW Jr. SUV: standard uptake or silly useless value? J Nucl Med 1995; 36: 1836-1839.

79. Bischof-Delaloye A, Wahl RL. How high a level of FDG abdominal activity is considered normal? J Nucl Med 1995; 36: $106 \mathrm{P}$.

80. Meyer MA. Diffusely increased colonic F-18 FDG uptake in acute enterocolitis. Clin Nucl Med 1995; 20: 434-435.

81. Pietrzyk Y, Scheidhauver K, Scharl A et al. Presurgical visualization of primary breast carcinoma with PET emission and transmission imaging. I Nucl Med 1995; 36: 1882-1884.

82. Wagner HN Jr. Positron emission tomography at the turn of the century. A perspective. Semin Nucl Med 1992; 22: 285-288.

83. Hoh CK, Hawkins RA, Glaspy J et al. Cancer detection with whole-body PET using 2-(F-18)-fluoro-2-deoxy-D-glucose. $J$ Comput Assist Tomogr 1993; 17: 582-589.

84. Lagrange JL, Maublant J, Darcourt J. Positron emission tomography: role of F-18 fluorodeoxyglucose imaging in oncology. Bull Cancer (Paris) 1995; 82: 611-622.

85. Rigo P, Paulus $P$, Jerusalem $G$ et al. Indications cliniques de la tomographie à positons au 18-FDG en oncologie. Expérience préliminaire et revue de la littérature. Médecine Nucléaire Imagerie Fonctionnelle et Métabolique 1995; 19: 73-89.

86. Shulkin BL, Mitchell DS, Ungar DR et al. Neoplasms in a pediatric population: 2-[F-18]-fluoro-2-deoxy-D-glucose PET studies. Radiology 1995; 194: 495-500.

87. Kole AC, Nieweg OE, Pruim J et al. Whole body PET with FDG: detection of unknown primary tumors. $J \mathrm{NuCl} \mathrm{Med}$ 1995; 36: 57P.

88. Kim EE, Chung SK, Haynie TP et al. Differentiation of residual or recurrent tumors from post-treatment changes with F-18 FDG PET. Radiographics 1992; 12: 269-279.

89. Di Chiro G, Brooks RA. PET-FDG of untreated and treated cerebral gliomas. J Nucl Med 1988; 29: 421-422.

90. Di Chiro G, Oldfield E, Wright DC et al. Cerebral necrosis after radiotherapy and/or intraarterial chemotherapy for brain tumors: PET and neuropathologic studies. Am J Roentgenol 1988; 150: 189-197.

91. Strauss LG, Clorius JH, Schlag P et al. Recurrence of colorectal tumors: PET evaluation. Radiology 1989; 170: 329-332

92. Coleman RE, Cascade E, Gupta NC et al. Clinical application and economic implications of PET in the assessment of solitary pulmonary nodules. A retrospective study. Abstract from the 1994 ICP Meeting, Institute for Clinical PET, Fairfax, Virginia.

93. Alavi JB, Alavi A, Chawluk J et al. Positron emission tomography in patients with glioma: a predictor of prognosis. Cancer 1988; 62: 1074-1078.

94. Reisser C, Haberkorn U, Strauss LG. The relevance of positron emission tomography for the diagnosis and treatment of head and neck tumors. J Otolaryngol 1993; 22: 231-238.

95. Quint LE, Francis IR, Wahl RL et al. Preoperative staging of non-small-cell carcinoma of the lung: imaging methods. Am J Roentgenol 1995; 164: 1349-1359.

96. Khouri NF et al. The solitary pulmonary nodule, assessment, diagnosis and management. Chest 1987; 91: 128-133.

97. Midthun DE, Swensen SJ, Pett JR. Clinical strategies for solitary pulmonary nodules. Ann Rev Med 1992; 93: 195-208.

98. Kubota K, Matsuzawa T, Fujiwara T et al. Differential diagnosis of lung tumor with positron emission tomography: a prospective study. $J$ Nucl Med 1990; 31: 1927-1992.

99. Dewan NA, Gupta NC, Redepenning LS et al. Diagnostic efficacy of PET-FDG imaging in solitary pulmonary nodules. Chest 1993; 104: 997-1002. 
100. Patz EL, Lowe VJ, Hoffman JM et al. Focal pulmonary abnormalities: evaluation with F-18 fluorodeoxyglucose PET scanning. Radiology 1993; 188: 487-490.

101. Slosman DO, Spiliopoulos A, Couson F et al. Satellite PET and lung cancer: a prospective study in surgical patients. Nucl Med Commun 1993; 14: 955-961.

102. Gupta NC, Frank AR, Dewan NA et al. Solitary pulmonary nodules: detection of malignancy with PET with 2-(F-18)fluoro-2-deoxy-D-glucose. Radiology 1992; 184: 441-444.

103. Gupta N, Chandramouli B, Reeb S, Dewan N. Diagnostic evaluation of solitary pulmonary nodules using PET-FDG imaging. I Nucl Med 1994; 35: 76P.

104. Scott WJ, Schwabe JL, Gupta NC et al. Positron emission tomography of lung tumors and mediastinal lymph nodes using [ ${ }^{18}$ F]fluorodeoxyglucose. Ann Thorac Surg 1994; 58: 698-703.

105. Dewan NA, Reeb SD, Gupta NC et al. PET-FDG imaging and transthoracic needle lung aspiration biopsy in evaluation of pulmonary lesions. A comparative risk-benefit analysis. Chest 1995; 108: 441-446.

106. Bury T, Paulus P, Corhay JL et al. Apport diagnostique de la tomographie à émission de positons dans l'évaluation d'une opacité pulmonaire unique: étude préliminaire chez 30 patients. Médecine Nucléaire, Imagerie Fonctionnelle et Métabolique 1996; 20: 77-82.

107. Bury T, Dowlati A, Paulus P et al. Evaluation of the solitary pulmonary nodule by positron emission tomography imaging. Eur Respir J 1996; 9: 410-414.

108. Bury T, Corhay JL, Paulus $P$ et al. Evaluation du nodule pulmonaire solitaire par la tomographie à émission de positons au 18-FDG. Rev Mal Respir 1995; 12: R81.

109. Kazerooni EA, Lim FT, Mikhail A, Martinez FJ. Risk of pneumothorax in CT-guided transthoracic needle aspiration biopsy of the lung. Radiology 1996; 198: 371-375.

110. Berlangieri SU, Scott AM, Knight $S$ et al. Mediastinal lymph node staging in non-small cell lung carcinoma: comparison of F-18-FDG positron emission tomography with surgical pathology. Eur J Nucl Med 1994; 21: S62.

111. Sasaki M, Ichiya Y, Kuwabara $Y$ et al. The usefulness of FDG-PET for the detection of mediastinal lymph node metastases in patients with non-small cell lung cancer. A comparative study with x-ray CT. Eur J Nucl Med 1994; 21 : S189.

112. Patz EF, Lowe VJ, Hoffman JM et al. Persistent or recurrent bronchogenic carcinoma: detection with PET and 2-(F-18)2-deoxy-D-glucose. Radiology 1994; 191: 379-382.

113. Patz EF Jr, Lowe VJ, Goodman PC, Herndon J. Thoracic nodal staging with PET imaging with 18 FDG in patients with bronchogenic carcinoma. Chest 1995; 108: 1617-1621.

114. Buchpiguel CA, Tse K, Alavi A et al. Use of quantitative FDG-PET whole body imaging in staging lung cancer. A comparison with CT. Eur I Nucl Med 1994; 21 : S61.

115. Lewis P, Griffin S, Marsden P et al. Whole-body ${ }^{18} \mathbf{F}$-fluorodeoxyglucose positron emission tomography in preoperative evaluation of lung cancer. Lancet 1994; 344: 1265-1266.

116. Chin R Jr, Ward R, Keyes JW et al. Mediastinal staging of non-small-cell lung cancer with positron emission tomography. Am J Resp Crit Care Med 1995; 152: 2090-2096.

117. Valk PE, Pounds TR, Hopkins DM et al. Staging non-small cell lung cancer by whole-body positron emission imaging. Ann Thorac Surg 1995; 60: 1573-1582.

118. Bury T, Dowlati A, Paulus P et al. Positron emission tomography versus computed tomography in the staging of mediastinal non-small cell lung cancer. Eur Respir J 1995; 22: 846.
119. Bury T, Corhay JL, Paulus P et al. La tomographie à émission de positons dans l'évaluation de l'extension ganglionnaire intrathoracique du cancer bronchique non grain d'avoine: étude préliminaire chez 30 patients. Rev Mal Respir 1996; 9: 410-414.

120. Bury T, Paulus P, Benoit T et al. Positron emission tomography versus computed tomography in the staging of mediastinal non-small cell lung cancer. Eur J Nucl Med 1995; 22: 846.

121. Boland GW, Goldberg MA, Lee MJ et al. Indeterminate adrenal mass in patients with cancer: evaluation at PET with 2-[F18]-fluoro-deoxy-D-glucose. Radiology 1995; 194: 131-134.

122. Bury T, Dowlati A, Paulus $P$ et al. Staging of non small cell lung cancer by whole-body ${ }^{18}$ FDG-PET. Eur $\mathrm{J} \mathrm{Nucl} \mathrm{Med}$ 1996; 23: 204-206.

123. Larcos G, Maisey MN. FDG-PET screening for cerebral metastasis in patients with suspected malignancy. Nucl Med Commun 1996; 17: 197-198.

124. Abe Y, Matsuzawa T, Fujiwara T et al. Clinical assessment of therapeutic effects on cancer using ${ }^{18} \mathrm{~F}$-2-fluoro-2-deoxyD-glucose and positron emission tomography: preliminary study of lung cancer. Intl J Radiat Oncol Biol Phys 1990; 19: 1005-1010.

125. Knopp MV, Bischoff H, Rimac A et al. Clinical utility of positron emission tomography with FDG for chemotherapy response monitoring - a correlative study of patients with small cell lung cancer. $J$ Nucl Med 1994; 35: 75P.

126. Hubner KF, Smith GT, Raja $S$ et al. Positron emission tomography for evaluating chest masses. J Nucl Med 1994; 35 : $220 \mathrm{P}$.

127. Hubner KF, Buonocore E, Singh SK et al. Characterization of chest masses by FDG positron emission tomography. Clin Nucl Med 1995; 20: 293-298.

128. Inoue T, Kim EE, Komaki R et al. Detecting recurrent or residual lung cancer with FDG-PET. $J$ Nucl Med 1995; 36 : $788-793$.

129. Duhaylongsod FG, Lowe VJ, Patz EF et al. Detection of primary and recurrent lung cancer by means of F-18 fluorodeoxyglucose positron emission tomography (FDG-PET). $J$ Thorac Cardiovasc Surg 1995; 110: 139-140.

130. Frank A, Lefkowitz D, Jaeger S et al. Decision logic for retreatment of asymptomatic lung cancer recurrence based on positron emission tomography findings. Int $J$ Radiat Oncol Biol Phys 1995; 32: 1495-1512.

131. Bury T, Paulus $P$, Weber T et al. Potential interest of pleural diseases evaluation with FDG-PET imaging: preliminary report. Eur J Nucl Med 1996; 23: 1186.

132. Lowe VJ, Patz E, Harris L et al. FDG-PET evaluation of pleural abnormalities. J Nucl Med 1994; 35: 228P.

133. Rege SD, Hoh CK, Glaspy JA et al. Imaging of pulmonary mass lesions with whole-body positron emission tomography and fluorodeoxyglucose. Cancer 1993; 72: 82-90.

134. Rhodes CG, Hughes JM. Pulmonary studies using positron emission tomography. Eur Respir J 1995; 8: 1001-1017.

135. Slosman DO, Spiliopoulos A, Keller A et al. Quantitative metabolic PET imaging of a plasma cell granuloma. $J$ Thorac Imaging 1994; 9: 116-119.

136. Tse KKM, Buchpiguel CA, Alavi JB et al. Detection and semi-quantitative measurement of lung cancer metabolic activity by whole body PET-FDG imaging. I Nucl Med 1994; 35: 226P

137. August DA, Ottow RT, Sugarbaker PH. Clinical perspectives on human colorectal cancer metastases. Cancer Metastasis Rev 1984; 3: 303-324. 
138. Moertel CG et al. An evaluation of the carcinoembryonic antigen (CEA) test for monitoring patients with resected colon cancer. JAMA 1993; 270: 943-947.

139. Cheu YM et al. Recurrent colorectal carcinoma. Evaluation with barium enema examination and CT. Radiology 1987; 163: $307-310$.

140. Moss MA. Imaging of colorectal carcinoma. Radiology 1989; 170: 308-310.

141. Yonekura $\mathrm{Y}$, Benua RS, Brill $\mathrm{AB}$ et al. Increased accumulation of 2-deoxy-2-( $\left.{ }^{18} \mathrm{~F}\right)$ fluoro-D-glucose in liver metastases from colon carcinoma. $J$ Nucl Med 1982; 23: 1133-1137.

142. Falk PM, Gupta NC, Thorson AG et al. Positron emission tomography for preoperative staging of colorectal carcinoma. Dis Colon Rectum 1994; 37: 153-156.

143. Gupta NC, Falk PM, Frank AL et al. Pre-operative staging of colorectal carcinoma using positron emission tomography. Nebr Med J 1993; 30-35.

144. Schlag P, Lehner B, Strauss LG et al. Scar or recurrent rectal cancer. Arch Surg 1989; 124: 197-200.

145. Ito $\mathrm{K}$, Kato $\mathrm{T}$, Tadokoro $\mathrm{M}$ et al. Recurrent rectal cancer and scar: differentiation with PET and MR imaging. Radiology 1992; 182: 549-552.

146. Schiepers C, Penninckx F, De Vadder N et al. Contribution of PET in the diagnosis of recurrent colorectal cancer: comparison with conventional imaging. Eur J Surg Oncol 1995; 21: $517-522$

147. Grabbe E, Winkler R. Local recurrence after sphincter-saving resection for rectal and rectosigmoid carcinoma: value of various diagnostic methods. Radiology 1985; 155: 305-310.

148. Beets G, Penninckx F, Schiepers $C$ et al. Clinical value of whole-body positron emission tomography with ${ }^{18} \mathrm{~F}$-fluorodeoxyglucose in recurrent colorectal cancer. Br J Surg 1994; 81: 1666-1671.

149. Gupta NC, Bowman BM, Frank AL et al. PET-FDG imaging for follow-up evaluation of treated colorectal cancer. Radiology 1991; 199: 181P.

150. Gupta N, Bradfield H. Role of positron emission tomography scanning in evaluating gastrointestinal neoplasms. Semin Nucl Med 1996; 26: 65-73.

151. Pounds TR, Valk PE, Haseman MK et al. Whole-body PETFDG imaging in diagnosis of recurrent colorectal cancer. $J$ Nucl Med 1995; 36: 57P.

152. Bohdiewicz PJ, Juni JE, Ball D, Dworkin H. Krukenberg tumor and lung metastases from colon carcinoma diagnosed with F-18 FDG PET. Clin Nucl Med 1995; 20: 419-420.

153. Bohdiewicz PJ, Scott GC, Juni JE et al. Indium-111 OncoScinti CR/OV and F-18 FDG in colorectal and ovarian carcinoma recurrences. Early observations. Clin Nucl Med 1995; 20: 230-236.

154. Daenen F, Hustinx H, Paulus P et al. Detection of recurrent colorectal carcinoma with whole-body FDG PET. $J$ Nucl Med 1996; 37; 261P.

155. Larson SM, Cohen AM, Cascade MBA. Clinical application and economic implications of PET in the assessment of colorectal cancer recurrence: a retrospective study. Abstract from the 1994 ICP Meeting, Institute for Clinical PET, Fairfax, Virginia.

156. Haberkorn U, Strauss L, Dimitrakopoulou A et al. PET studies of fluorodeoxyglucose metabolism in patients with recurrent colorectal tumors receiving radiotherapy. $J \mathrm{Nucl} \mathrm{Med}$ 1991; 32: 1485-1490.

157. Engenhart R, Kimmig BN, Straub LG et al. Therapy monitoring of presacral recurrences after high-dose irradiation: value of PET, CT, CEA and pain score. Strahlenther Onkol 1992; 168: 203-212.

158. Hawkins R. Pancreatic tumors: imaging with PET. Radiology 1995 ; 95 : $320-322$.

159. Megibow AJ, Zhou XH, Rotterdam H et al. Pancreatic adenocarcinoma: CT versus MR imaging in the evaluation of resectability - Report of the Radiology Diagnostic Oncology Group. Radiology 1995; 195: 327-332.

160. Syrota A, Duquesnoy N, Paraf M et al. The role of positron emission tomography in the detection of pancreatic disease. Radiology 1992; 143: 249-253.

161. Kirchner PT, Ryan J, Zalutsky M et al. Positron emission tomography for the evaluation of pancreatic disease. Semin Nucl Med 1980; 10: 374-391.

162. Kubo S, Yamamoto K, Magata Y et al. Assessment of pancreatic blood flow with positron emission tomography and oxygen-15-water. Ann Nucl Med 1991; 5: 133-138.

163. Bares R, Klever P, Hauptmann S et al. F-18 fluorodeoxyglucose PET in vivo evaluation of pancreatic glucose metabolism for detection of pancreatic cancer. Radiology 1994; 192: 79-86.

164. Friess H, Langhans J, Ebert $\mathrm{M}$ et al. Diagnosis of pancreatic cancer by $2\left[{ }^{18} \mathrm{~F}\right]-$ fluoro-2-deoxy-D-glucose positron emission tomography. Gut 1995; 365: 771-777.

165. Inokuma T, Tamaki N, Torizuka $T$ et al. Evaluation of pancreatic tumors with positron emission tomography and F-18 fluorodeoxyglucose: comparison with CT and US. Radiology $1995 ; 195: 345-352$.

166. Inokuma $\mathrm{T}$, Tamaki $\mathrm{N}$, Torizuka $\mathrm{T}$ et al. Value of fluorine18-fluorodeoxyglucose and thallium-201 in the detection of pancreatic cancer. $J$ Nucl Med 1995; 36: 229-235.

167. Klever P, Bares R, Fass J et al. PET with fluorine 18 deoxyglucose for pancreatic disease. Lancet 1992; 340: 11581159.

168. Stollfuss JC, Glatting G, Friess $H$ et al. 2-(fluorine-18)-fluoro-2-deoxy-glucose PET in detection of pancreatic cancer: value of quantitative image interpretation. Radiology 1995; 195: 339-344.

169. Benyounes H, Smith FW, Campbell C et al. Superimposition of PET images using ${ }^{18} \mathrm{~F}$-fluorodeoxyglucose with magnetic resonance images in patients with pancreatic carcinoma. Nucl Med Commun 1995; 16: 575-580.

170. Fukunaga T, Enomoto K, Okazumi S et al. Analysis of glucose metabolism in patients with esophageal cancer by PET: estimation of hexokinase activity in the tumor and usefulness for clinical assessment using ${ }^{18} \mathrm{~F}$-fluorodeoxyglucose. $J J p n$ Surg Soc 1994; 95: 317-325.

171. Yasuda S, Raja S, Hubner KF. Application of whole-body positron emission tomography in the imaging of esophageal cancer: report of a case. Surgery Today 1995; 25: 261-264.

172. Baker ME, Pelley R. Hepatic metastases: basic principles and implications for radiologists. Radiology 1995; 197 : 329-337.

173. Ohashi I, Hanafusa K, Hanafusa K, Yoshida T. Small hepatocellular carcinomas: two-phase dynamic incremental CT in detection and evaluation. Radiology 1993; 189: 851-855.

174. Hollett MD, Jeffrey RB Jr, Nino-Murcia M et al. Dual-phase helical CT of the liver: value of arterial phase scans in the detection of small $(\leq 1.5 \mathrm{~cm})$ malignant hepatic neoplasms. AJR 1995; 164: 879-884.

175. Gupta N, Frank A, Mailliard J et al. Accurate detection of liver metastases in patients with primary malignancies using PET-FDG imaging. $J$ Nucl Med 1993; 34: 6P. 
176. Shields AT, Graham MM, Helton S et al. Utility F-18 FDG PET in preoperative evaluation of patients with colon carcinoma metastatic to liver. $J$ Nucl Med 1995; 36: 106P.

177. Hustinx R, Paulus $P$, Daenen $F$ et al. PET imaging of liver metastases: a retrospective study. J Nucl Med 1996; 37: 250P.

178. Messa C, Choi Y, Ho C et al. Quantitative evaluation of glucose utilization in liver metastases, parametric imaging of FDG uptake with PET. I Comput Assist Tomogr 1992; 16: $684-689$

179. Nagata Y, Yamamoto K, Hiraoka M et al. Monitoring liver tumor therapy with ${ }^{18} \mathrm{~F}-\mathrm{FDG}$ positron emission tomography. $J$ Comput Assist Tomogr 1990; 14: 370-374.

180. Enomoto K, Fukanaga T, Okazumi $\mathrm{S}$ et al. Can fluorodeoxyglucose-positron emission tomography evaluate the functional differentiation of hepatocellular carcinoma? Kaku Igaku 1991; 28: 1353-1356.

181. Torizuka T, Tamaki N, Inokuma $\mathrm{T}$ et al. Value of fluorine18-FDG-PET to monitor hepatocellular carcinoma after interventional therapy. $J$ Nucl Med 1994; 35: 1965-1969.

182. Torizuka T, Tamaki N, Inokuma $\mathrm{T}$ et al. In vivo assessment of glucose metabolism in hepatocellular carcinoma with FDG-PET. $J$ Nucl Med 1995; 36: 1811-1817.

183. Paul R. Comparison of fluorine-18-2-fluorodeoxyglucose and gallium-67 citrate imaging for detection of lymphoma. $J$ Nucl Med 1987; 28: 288-292.

184. Bares R, Horstmann K, Altehoefer C et al. F-18 deoxyglucose (FDG) PET to assess local effects of radiation or chemotherapy in patients with malignant lymphoma. $\mathrm{J} \mathrm{Nucl}$ Med 1991; 32: 918.

185. Newman JS, Francis IR, Kaminski MS, Wahl RL. Imaging of lymphoma with PET with 2-[F-18]-fluoro-2-deoxy-D-glucose: correlation with CT. Radiology 1994; 190: 111-116.

186. Lapela L, Leskinen S, Minn HR et al. Increased glucose metabolism in untreated non-Hodgkin's lymphoma: a study with positron emission tomography and fluorine-18-fluorodeoxyglucose. Blood 1995; 86: 3522-3527.

187. Okada J, Yoshikawa K, Imazeki $\mathrm{K}$ et al. The use of FDGPET in the detection and management of malignant lymphoma: correlation of uptake with prognosis. J Nucl Med 1991; 32: 686-691.

188. Jerusalem G, Paulus P, Warland V et al. Whole-body positron emission tomography using ${ }^{18} \mathbf{F}$-fluorodeoxyglucose in the staging of Hodgkin's disease and non-Hodgkin's lymphoma. Eur J Nucl Med 1995; 22: 786.

189. Jerusalem G, Fassotte MF, Paulus $P$ et al. Whole-body positron emission tomography for staging, response evaluation and follow-up of Hodgkin's disease and non-Hodgkin lymphoma. Blood 1995; 86 Suppl 1: 534a.

190. Royal HD. Clinical applications of positron emission tomography in cancer: the good, the bad and the ugly. $\mathrm{J} \mathrm{NuCl} \mathrm{Med}$ 1992; 33: 330-332.

191. Yoshikawa K, Okada J, Uno K et al. Evaluation of therapeutic effect on the malignant lymphoma by dynamic positron emission tomographic technique using fluorine-18 2-deoxy2-fluoro-D-glucose. $J$ Nucl Med 1989; 30: 910.

192. Hoekstra OS, Ossenkoppele GJ, Golding R et al. Early treatment response in malignant lymphoma as determined by planar fluorine-18-fluorodeoxyglucose scintigraphy. $J \mathrm{Nucl}$ Med 1993; 34: 1706-1710.

193. Bares R, Altehoefer C, Cremerius U et al. FDG-PET for metabolic classification of residual lymphoma after chemotherapy. $J$ Nucl Med 1994; 35: 131P.
194. Okada J, Oonishi H, Yoshikawa K., et al. FDG-PET for predicting the prognosis of malignant lymphoma. Ann $\mathrm{Nucl}$ Med 1994; 8: 187-191.

195. Leskinen-Kallio S, Ruotsalainen U, Nagren K et al. Uptake of carbon-11-methionine and fluorodeoxyglucose in nonHodgkin's lymphoma: a PET study. J Nucl Med 1991; 32: 1211-1218.

196. Bares R, Galonska P, Dempke W et al. Somatostatin receptor scintigraphy in malignant lymphoma: first results and comparison with glucose metabolism measured by positronemission tomography. Horm Metab Res Suppl 1993; 27: $56-58$.

197. Schonberger JA, Stollfuss JC, Kocher F et al. Whole body 18-FDG-PET for staging of malignant lymphomas. Eur $J$ Nucl Med 1994; 21: 727.

198. Wahl RL, Hawkins RA, Larson SM et al. Proceedings of a national cancer institute workshop: PET in oncology - a clinical research agenda. Radiology 1994; 193: 604-606.

199. Paulus P, Jerusalem G, Warland V et al. Apport de la tomographie à émission de positons (TEP) au 18-FDG corps entier dans le bilan d'extension, l'évaluation de l'efficacité thérapeutique et le suivi clinique des lymphomes hodgkiniens et non-hodgkiniens. Médecine Nucléaire - Imagerie Fonctionnelle et Métabolique 1995; 19: 7/9: 421.

200. Rigo P, Jerusalem G, Paulus P et al. Positron emission tomography using $18 \mathrm{~F}$-fluorodeoxyglucose in response evaluation and follow-up of Hodgkin's disease and non-Hodgkin's lymphoma [abstract]. Eur J Nucl Med 1995; 22:786.

201. Dimitrakopoulou-Strauss A, Strauss LG, Glodschmidt $\mathrm{H}$ et al. Evaluation of tumor metabolism and multidrug resistance in patients with treated malignant lymphomas. Eur $J$ NuCl Med 1994; 21: 727.

202. Minn H, Paul R, Ahonen A. Evaluation of treatment response to radiotherapy in head and neck cancer with fluorine-18-fluorodeoxyglucose. J Nucl Med 1988; 29: 15211525 .

203. Leskinen-Kallio $S$, Lindholm P, Lapela $M$ et al. Imaging of head and neck tumors with positron emission tomography and [C-11] methionine. Int J Radiat Oncol Biol Phys 1994; 30: 1195-1199.

204. Lindholm P, Leskinen-Kallio S, Minn H et al. Comparison of fluorine-18-fluorodeoxyglucose and carbon-11-methionine in head and neck cancer. $J$ Nucl Med 1993; 34: 1711-1716.

205. Moreau P, Goffart Y, Collignon J. Computed tomography of metastatic cervical lymph nodes. Arch Otolaryngol Head Neck Surg 1990; 116: 1190-1193.

206. Greven KM, McGuirt WF, Watson X et al. PET in the evaluation of laryngeal carcinoma. Ann Otol Rhinol Laryngol 1995; 104: 274-278.

207. Rege S, Mass A, Chaiken L et al. Use of positron emission tomography with fluorodeoxyglucose in patients with extracranial head and neck cancers. Cancer 1994; 73; 3047-3058.

208. Wong WL, Chevretton E, McGurk M, Croft D. PET-FDG imaging in the clinical evaluation of head and neck cancer. $J$ $R$ Soc Med 1995; 88: P469-P473.

209. Zeitouni AG, Yamamoto YL, Black M, Gjedde A. Functional imaging of head and neck tumors using positron emission tomography. J Otolaryngol 1994; $23: 77-80$.

210. Bailet JW, Sercarz JA, Abemayor $\mathrm{E}$ et al. The use of positron emission tomography for early detection of recurrent head and neck squamous cell carcinoma in postradiotherapy patients. Laryngoscope 1995; 105: 135-139. 
211. Jabour BA, Choi Y, Hoh CK et al. Extracranial head and neck: PET imaging with 2-(F-18)-fluoro-2-deoxy-D-glucose and MR imaging correlation. Radiology 1993; 186: 27-35.

212. McGuirt WF, Greven KM, Keyes JW et al. Positron emission tomography in the evaluation of laryngeal carcinoma. Ann Otol Rhinol Laryngol 1995; 104: 274-278.

213. McGuirt WF, Keyes JW, Greven KM et al. Preoperative identification of benign versus malignant parotid masses: a comparative study including positron emission tomography. Laryngoscope 1995; 105: 579-584.

214. Keyes JW Jr, Harkness BA, Greven KM et al. Salivary gland tumors: pretherapy evaluation with PET. Radiology 1994; 1992: 99-102.

215. Laubenbacher C, Saumweber D, Wagner-Manslau C et al. Comparison of fluorine-18-fluorodeoxyglucose PET, MRI and endoscopy for staging head and neck squamous-cell carcinomas. J Nucl Med 1995; 36: 1747-1757.

216. Braams JW, Pruim J, Freling NJL et al. Detection of lymph node metastases of squamous-cell cancer of the head and neck with FDG-PET and MRI. J Nucl Med 1995; 36: 211-216.

217. Paulus P, Moreau P, Sambon A et al. Contribution of positron emission tomography imaging with ${ }^{18} \mathrm{~F}$-fluorodeoxyglucose to presurgical loco-regional lymph node staging of head and neck tumors. Eur J Nucl Med 1995; 22: 659.

218. Lee TH, Anzai Y, Huda A et al. Positron emission tomographic imaging of the head and neck. West J Med 1993; 159: 72.

219. Lehmann W, Benchaou M, Slosman DO et al. Positron emission tomography in the preoperative evaluation of cervical lymph node metastasis of ORL cancer. Schweiz Rundsch Med Prax 1993; 82: 1457-1461.

220. Bailet JW, Abemayor E, Jabour BA et al. Positron emission tomography: a new, precise imaging modality for detection of primary head and neck tumors and assessment of cervical adenopathy. Laryngoscope 1992; 102: 281-288.

221. Mancuso AA, Drane WE, Mukherji SK. The promise FDG in diagnosis and surveillance of head and neck cancer. Cancer 1994; 74: 1193-1195.

222. Rege SD, Chaiken L, Hoh CK et al. Change induced by radiation therapy in FDG uptake in normal and malignant structures of the head and neck: quantitation with PET, Radiology 1993: 189: 807-812.

223. Greven KM, Williams DW, Keyes JW et al. Positron emission tomography of patients with head and neck carcinoma before and after high dose irradiation. Cancer 1994; 74: 1355-1359.

224. Mukherji SK, Drane WE, Tart RP et al. Comparison of thallium-201 and F-18 FDG SPECT uptake in squamous cell carcinoma of the head and neck. Am J Neuroradiol 1994; 15: 1837-1842.

225. Chaiken L, Rege $\mathrm{S}$, Hoh $\mathrm{C}$ et al. Positron emission tomography with fluorodeoxyglucose to evaluate tumor response and control after radiation therapy. Int J Radiat Oncol Biol Phys 1993; 27: 455-464.

226. Greven KM, Williams DW, Keyes JW et al. Distinguishing tumor recurrence from irradiation sequelae with positron emission tomography in patients treated for larynx cancer. Int J Radiat Oncol Biol Phys 1994; 29: 841-845.

227. Haberkorn U, Strauss LG, Reisser $C$ et al. Positronenemissionstomographie (PET) fur Beurteilung von Tumorproliferation und Therapieverlauf bei HNO-Tumoren. Radiologe 1992; 32: 296-301.
228. Haberkorn U, Strauss LG, Dimitrakopolou A et al. Fluorodeoxyglucose imaging of advanced head and neck cancer after chemotherapy. J Nucl Med 1993; 34: 12-17.

229. Reisser C, Haberkorn U, Dimitrakopoulou-Strauss A et al. Chemotherapeutic management of head and neck malignancies with positron emission tomography. Arch Otolaryngol Head Neck Surg 1995; 121: 272-276.

230. Miller BA, Feuer EJ, Hankey BF. Recent incidence trends of breast cancer in women and the relevance of early detection. An update. CA Cancer J Clin 1993; 43: 27-41.

231. Anderson I, Aspergen K, Janzow L et al. Mammographic screening and mortality from breast cancer: the Malmo Mammographic Screening Trial. Br Med J 1988; 297 : $943-948$.

232. Boring CC, Suires TS, Tong T. Cancer statistics 1993. CA Cancer J Clin 1993; 43: 7-26.

233. Early Breast Cancer Trialists' Collaborative Group. Systemic treatment of early breast cancer by hormonal, cytotoxic, or immune therapy. 133 randomised trials involving 31000 recurrences and 24000 deaths among 75000 women. Lancet 1992; 339: 1-15, 71-85.

234. Danforth DN. The role of axillary lymph node dissection in the management of breast cancer. Principles and Practice of Oncology 1992; 6: 1-16.

235. Dehdashti F, McGuire AH, Van Brocklin F et al. Assessment of $21-\left({ }^{18 F}\right)$ fluoro- $16 \alpha$-ethyl-19-norprogesterone as a positron-emitting radiopharmaceutical for the detection of progestin receptors in human breast carcinomas. $J$ Nucl Med 1991; 32: 1532-1537.

236. McGuire AH, Dehdashti F, Siegel BA et al. Positron tomographic assessment of $16 \alpha-(18 \mathrm{~F})$ fluoro-17 $\beta$-estradiol uptake in metastatic breast carcinoma. J Nucl Med 1991; 32: 1526-1531.

237. Mintun MA, Welch MJ, Siegel BA et al. Breast cancer: PET imaging of estrogen receptors. Radiology 1988; 169: 45-48.

238. Elston CW. Grading of invasive carcinoma of the breast. In: Page DL, Anderson TJ, eds. Diagnostic histopathology of the breast. New York: Churchill Livingstone, 1987.

239. Paik S, Hazan R, Fisher ES. Pathologic findings from the National Surgical Adjuvant Breast and Bowel Project: prognostic significance of $e r b \mathrm{~B}-2$ protein overexpression in primary breast cancer. J Clin Oncol 1990; 8: 103-112.

240. Bruce DM, Evans NT, Heys SD et al. Positron emission tomography: 2-deoxy-2-[18F]-fluoro-D-glucose uptake in locally advanced breast cancers. Eur J Surg Oncol 1995; 21: 280-283.

241. Crowe JP, Adler LP, Shenk RR et al. Positron emission tomography and breast masses: comparison with clinical, mammographic and pathological findings. Ann Surg Oncol 1994; 1: 132-140.

242. Dehdashti F, Mortimer JE, Siegel BA et al. Positron tomographic assessment of estrogen receptors in breast cancer: comparison with FDG-PET and in vitro receptor assays. $J$ Nucl Med 1995; 36: 1766-1774.

243. Tse NY, Hoh CK, Hawkins RA et al. The application of positron emission tomographic imaging with fluorodeoxyglucose to the evaluation of breast disease. Ann Surg 1992; 216: 27-34.

244. Zasadny KR, Wahl RL. Enhanced FDG-PET tumor imaging with correlation-coefficient filtered influx-constant images. $J$ Nucl Med 1996; 37: 371-374.

245. Minn H, Soini I. $\left({ }^{18} \mathrm{~F}\right)$ Fluorodeoxyglucose scintigraphy in diagnosis and follow-up of treatment in advanced breast cancer. Eur J Nucl Med 1989; 15: 61-66. 
246. Wahl RL, Cody R, Hutchins G et al. Positron emission tomographic scanning of primary and metastatic breast with the radiolabeled glucose analogue 2-deoxy-2( $\left.{ }^{18} \mathrm{~F}\right)$ fluoro-Dglucose. N Engl J Med 1991; 324: 200.

247. Wahl RL, Cody RL, Hutchins GD, Mudgett EE. Primary and metastatic breast carcinoma: initial clinical evaluation with PET with the radiolabeled glucose analogue 2-[F-18]-fluoro2-deoxy-D-glucose. Radiology 1991; 179: 765-770.

248. Kubota K, Matsuzawa T, Ameniya A et al. Imaging of breast cancer with $\left({ }^{18} \mathrm{~F}\right)$ fluorodeoxyglucose and positron emission tomography. I Comput Assist Tomogr 1989; 13: 1097-1098.

249. Nieweg OE, Kim EE, Wong WH et al. Positron emission tomography with fluorine-18-deoxyglucose in the detection and staging of breast cancer. Cancer 1993; 71: 3920-3925.

250. Nieweg OE, Wong WH, Singletary SE et al. Positron emission tomography of glucose metabolism in breast cancer. Potential for tumor detection, staging and evaluation of chemotherapy. Ann NY Acad Sci 1993; 698: 423-428.

251. Adler LP, Crowe JP, Al-Kaisi NK, Sunshine JL. Evaluation of breast masses and axillary lymph nodes with (F-18)2-deoxy-2-fluoro-D-glucose PET. Radiology 1993; 187: $743-$ 750 .

252. Adler DD, Wahl RL. New methods for imaging the breast: techniques, findings, and potential. Am J Roentgenol 1995; 164: 19-30.

253. Avril N, Janicke F, Dose $\mathbf{J}$ et al. Imaging of breast tumors with FDG-PET in comparison with histology. Eur $J$ Nucl Med 1994; $21: 749$.

254. Wahl RL, Helvie MA, Chang AE, Andersson I. Detection of breast cancer in women after augmentation mammoplasty using fluorine-18-fluorodeoxyglucose-PET. $J$ Nucl $\mathrm{Med}$ 1994; 35: 872-875.

255. Cady B. The need to reexamine axillary lymph node dissection in invasive breast cancer. Cancer 1994; 73: 505-508.

256. March DE, Wechsler RJ, Kurtz AB et al. CT-pathologic correlation of axillary lymph nodes in breast carcinoma. $J$ Comput Assist Tomogr 1991; 15: 440-444.

257. Adler LP, Cascade E, Crowe J et al. Axillary lymph node involvement in breast cancer: a retrospective study. Abstract from the 1994 ICP Meeting, Institute for Clinical PET, Fairfax, Virginia.

258. Petren-Mallmin M. Clinical and experimental imaging of breast cancer metastases in the spine. Acta Radiol Suppl 1994; 391: 1-23.

259. Wahl Rl, Zasadny K, Helvie M et al. Metabolic monitoring of breast cancer chemohormonotherapy using positron emission tomography. Initial evaluation. $J$ Clin Oncol 1993; 11: 2101-2111.

260. Jansson T, Westlin JE, Ahlstrom $H$ et al. Positron emission tomography studies in patients with locally advanced and/or metastatic breast cancer: a method for early therapy evaluation. J Clin Oncol 1995; 13: 1470-1477.

261. Uren RF, Howman-Giles RB, Shaw HM et al. Lymphoscintigraphy in high-risk melanoma of the trunk: predicting draining node groups, defining lymphatic channels and locating the sentinel node. J Nucl Med 1993; 34: 1435-1440.

262. Buzaid AC, Sandler AB, Maani $S$ et al. Role of computed tomography in the staging of primary melanoma. $J$ Clin Oncol 1993; 11: 638-643.

263. Wahl RL, Hutchins GD, Buchsbaum DJ et al. Fluorine-18-2deoxy-2-fluoro-D-glucose (FDG) uptake into human tumor xenografts: feasibility studies for cancer imaging with PET. Cancer 1991; 67: 1544-1549.
264. Gritters LS, Francis IR, Zasadny KR. et al. Initial assessment of positron emission tomography using 2-fluorine-18fluoro-deoxy-D-glucose in the imaging of malignant melanoma. I Nucl Med 1993; 34: 1420-1427.

265a. Boni R, Boni RA, Steinert $\mathrm{H}$ et al. Staging of metastatic melanoma by whole-body positron emission tomography using 2-fluorine-18-fluoro-2-deoxy-D-glucose. $\mathrm{Br} J$ Dermatol 1995; 132: 556-562.

265b. Steinert HC, Boni RAH, Buck A et al. Malignant melanoma: staging with whole-body positron emission tomography and 2-[F-18]-fluoro-2-deoxy-D-glucose. Radiology 1995; 195: 705-709.

266. Strauss LG, Dimitrakopoulou-Strauss A, van Kaick G. PET studies with F-18-deoxyglucose in patients with metastatic melanoma prior and after therapy. $J$ Nucl Med 1994; 35: $38 \mathrm{P}$.

267. Blessing C, Feine U, Geiger L et al. Positron emission tomography and ultrasonography. A comparative retrospective study assessing the diagnostic validity in lymph node metastases of malignant melanoma. Arch Dermatol 1995; 131: 1394-1398.

268. Bhattathiry M, Glass E, Kirgan D et al. Efficacy of FDG whole body PET in staging and clinical management of metastatic malignant melanoma. J Nucl Med 1994; 35: 230P.

269. Kirgan D, Guenther J, Bhattathiry $M$ et al. The importance of whole-body PET scans on the management of metastatic malignant melanoma. Prog Proc Annu Meet Am Soc Clin Oncol 1994; 13: 396.

270. Yao WJ, Hoh CK, Glaspy JA et al. Whole body FDG PET imaging for staging of malignant melanoma: is it cost effective? I Nucl Med 1994; 35: 8P.

271. Bloom AD, Adler LP, Shuck JM. Determination of malignancy of thyroid nodules with positron emission tomography. Surgery 1993; 114: 728-735.

272. Adler LP, Bloom AD. Positron emission tomography of thyroid masses. Thyroid 1993; 3: 195-200.

273. Joensuu H, Ahonen A, Klemi PJ. 18F-Fluorodeoxyglucose imaging in preoperative diagnosis of thyroid malignancy. Eur J Nucl Med 1988; 13: 502-506.

274. Joensuu $H$, Ahonen A. Imaging of metastases of thyroid carcinoma with fluorine-18 fluorodeoxyglucose. $J \mathrm{Nucl}$ Med 1987; 28: 910-914.

275. Fridrich L, Messa C, Landoni $C$ et al. PET/(F-18)FDG and I-131 scintigraphy in patients with thyroid carcinoma. Eur J Nucl Med 1994; 2: 780.

276. Scott GC, Meier DA, Dickinson CZ. Cervical lymph node metastasis of thyroid papillary carcinoma imaged with fluorine-18-FDG, technetium-99m-pertechnetate and iodine131-sodium iodide. J Nucl Med 1995; 36: 1843-1945.

277. Feine U, Lietzenmayer R, Hanke JP et al. 18FDG wholebody PET in differentiated thyroid carcinoma. Flipflop in uptake patterns of 18 FDG and ${ }^{131}$ I. Nuklearmedizin 1995; 34: 127-134.

278. Grunwald F, Schomburg A, Bender $\mathrm{H}$ et al. Fluorine-18 fluorodeoxyglucose positron emission tomography in the follow-up of differentiated thyroid cancer. Eur $J$ Nucl Med 1996; 23: 312-319.

279. Sisson JC, Ackermann RJ, Meyer MA et al. Uptake of 18fluoro-2-deoxy-D-glucose by thyroid cancer: implications for diagnosis and therapy. $J$ Clin Endocrinol Metab 1993; 77: $1090-1094$. 
280. The Western PET Association. Positron emission tomography. Applications in clinical oncology: an annotated bibliography.

281. Neumann DR, Esselstyn CB, MacIntyre WJ et al. Primary hyperparathyroidism: preoperative parathyroid imaging with regional body FDG PET. Radiology 1994; 192: 509-512.

282. Sisson JC, Thompson NW, Ackerman RJ, Wahl RL. Use of 2-(F-18)-fluoro-2-deoxy-D-glucose PET to locate parathyroid adenomas in primary hyperparathyroidism. Radiology 1994; 192: 280.

283. Shulkin BL, Koeppe RA, Francis IR et al. Pheochromocytomas that do not accumulate metaiodobenzylguanidine: localization with PET and administration of FDG. Radiology 1993; 186: 11-15.

284. Vaidyanathan G, Affleck DJ, Zalutsky MR. Validation of 4 [fluorine-18]fluoro-3-iodobenzylguanidine as a positronemitting analog of MIBG. $J$ Nucl Med 1995; 36: 644-650

285. Shulkin BL, Sisson JC, Hutchinson RJ. PET FDG studies of neuroblastoma. I Nucl Med 1994; 35: 135P.

286. Abrams HL, Spiro R, Goldstein N. Metastases in carcinoma: analysis of 1000 autopsied cases. Cancer 1950; 3: 74-85.

287. Dunnick NR. Adrenal imaging: current status. AJR 1990; 154: 927-936.

288. Ahlstrom H, Eriksson B, Bergstrom $M$ et al. Pancreatic neuroendocrine tumors: diagnosis with PET. Radiology 1995; 195: 333-337.

289. Foidart-Willems J, Depas G, Vivegnis D et al. Positron emission tomography and radiolabelled octreotide scintigraphy in carcinoid tumors [abstract]. Eur J Nucl Med 1995; 22: 635.

290. Muhr C, Bergström M. Positron emission tomography applied in the study of pituitary adenomas. $J$ Endocrinol Invest $1991 ; 14: 509-528$.

291. Bergström M, Muhr C, Lundberg PO, Langström B. PET as a tool in the clinical evaluation of pituitary adenomas. $J \mathrm{Nucl}$ Med 1991; 32: 610-615.

292. Kern KA, Brunetti A, Norton JA et al. Metabolic imaging of human extremity musculoskeletal tumors by PET. $J$ Nucl Med 1988; 29: 181-186.

293. Nieweg OR, Pruim J, van Ginkel RJ et al. Fluorine-18-fluorodeoxyglucose PET imaging of soft-tissue sarcoma. $J$ Nucl Med 1996; 37: 257-261

294. Griffeth LK, Dehdashti F, McGuire AH et al. PET evaluation of soft-tissue masses with fluorine-18 fluoro-2-deoxy-D-glucose. Radiology 1992; 182: 185-194.

295. Nieweg OE, Pruim J, Hoekstra HJ et al. Positron emission tomography with fluorine-18-fluorodeoxyglucose for the evaluation of therapeutic isolated regional limb perfusion in a patient with soft-tissue sarcoma. J Nucl Med 1994; 35: 90-92.

296. Jones DN, Brizel DM, Charles HC et al. Monitoring of response to neoadjuvant therapy of soft tissue and musculoskeletal sarcomas using F-18-FDG PET. J Nucl Med 1994; 35: $38 \mathrm{P}$.

297. Tse N, Hoh C, Hawkins R et al. Positron emission tomography diagnosis of pulmonary metastases in osteogenic sarcoma. Am J Clin Oncol 1994; 17: 22-25.

298. Einhorn W, Nilsson B, Stovall K. Factors influencing survival in carcinoma of the ovary. Cancer 1985; 55: 2015-2019.

299. Wahl RL, Hutchins GD, Roberts J. FDG-PET imaging of ovarian cancer: initial evaluation in patients. $J$ Nucl $\mathrm{Med}$ 1991: 32: 982

300. Hubner KF, McDonald TJ, Niethammer JR et al. Assessment of primary and metastatic ovarian cancer by positron emis- sion tomography using 2-( $\left.{ }^{18} \mathrm{~F}\right)$-deoxyglucose. Gynecol Oncol 1993; 51: 197-204

301. Hubner KF. Clinical applications of PET in ovarian cancer: an alternative to second look surgery. In: Proceedings 7 th Annual International PET Conference, Institute for Clinical PET, Fairfax, Virginia, 1995.

302. Karlan BY, Hawkins R, Hoh C et al. Whole-body positron emission tomography with $2-\left({ }^{18} \mathrm{~F}\right)$-fluoro-2-deoxy-D-glucose can detect recurrent ovarian carcinoma. Gynecol Oncol 1993; 51: 175-181.

303. Casey MJ, Gupta NC, Muths CK. Experience with positron emission tomography (PET) scans in patients with ovarian cancer. Gynecol Oncol 1994; 53: 331-338.

304. Avril N, Janicke F, Dose J et al. FDG-PET evaluation of pelvic masses suspicious for primary or recurrent ovarian cancer. $J$ Nucl Med 1994; 35: 231P.

305. Kawamura J, Hida S, Yoshida $\mathrm{O}$ et al. Validity of positron emission tomography using 2-deoxy-2-18F-fluoro-D-glucose in patients with renal cell carcinoma (preliminary report). Kaku Igaku 1988; 25: 1143-1148.

306. Wahl RL, Harney J, Hutchins G, Grossman HB. Imaging of renal cancer using positron emission tomography with 2-deoxy-2-(18F)-fluoro-D-glucose: pilot animal and human studies. J Urol 1991; 146: 1470-1474.

307. Harney JV, Wahl RL, Liebert M et al. Uptake of 2-deoxy,2deoxy, 1-( $\left.{ }^{18} \mathrm{~F}\right)$ fluoro-D-glucose in bladder cancer: animal localization and initial patient positron emission tomography. $J$ Urol 1991; 145: 279-283.

308. Kocher F, Grimmel S, Hautmann R et al. Preoperative lymph nodes tagging in patients with kidney and urinary bladder neoplasm. J Nucl Med 1994; 35: 223P.

309. Wahl RL, Greenough R, Clarke MF, Grossman HB. Initial evaluation of FDG/PET imaging of metastatic testicular neoplasms. $J$ Nucl Med 1993; 34: 6P.

310. Wilson CB, Young HE, Ott RJ et al. Imaging metastatic testicular germ cell tumours with [18]FDG positron emission tomography: prospects for detection and management. Eur $J$ Nucl Med 1995; 22: 508-513.

311. Wahl RL. Emerging applications of PET in oncology: melanoma, lymphoma and prostate cancer. Proceedings, Sixth Annual International PET Conference, Institute for Clinical PET 1994, Fairfax, Virginia, USA.

312. Laubenbacher C, Hofer C, Avril $N$ et al. Can 18-FDG PET differentiate local recurrent prostatic cancer and scar? Eur $J$ Nucl Med 1995; 22: 803.

313. Shreeve P, Grossman HB, Wahl RL. Initial assessment of FDG/PET detection of skeletal metastatic prostate carcinoma. I Nucl Med 1993; 34: 223P.

314. Delbeke D, Meyerowitz C, Lapidus RL et al. Optimal cutoff levels of F-18 fluorodeoxyglucose uptake in the differentiation of low-grade from high-grade brain tumors with PET. Radiology 1995; 195: 47-52.

315. Sasaki M, Ichiya Y, Kuwabara $Y$ et al. Ringlike uptake of [18F]FDG in brain abscess: a PET study. J Comput Assist Tomogr 1990; 14: 486-487.

316. Ishii $\mathrm{K}$, Ogawa T, Hatazawa J et al. High L-methyl-[ $\left.{ }^{11} \mathrm{C}\right] \mathrm{me}-$ thionine uptake in brain abscess: a PET study. $J$ Comput Assist Tomogr 1993; 17: 660-661.

317. Hoffman JM, Waskin HA, Schifter T et al, FDG-PET in differentiating lymphoma from non malignant central nervous system lesions in patients with AIDS. J Nucl Med 1993; 34 : $567-75$. 
318. Dethy S, Goldman S, Bleçis S et al. ${ }^{11} \mathrm{C}$-methionine and fluorine-18 FDG PET study in brain hematoma. $\mathrm{J} \mathrm{Nucl} \mathrm{Med}$ 1994; 35: 1162-1166.

319. Ericson K, Lilja A, Bergström M et al. Positron emission tomography with ([1 $\left.{ }^{11} \mathrm{C}\right]$ methyl)-L-methionine, $\left[{ }^{11} \mathrm{C}\right] \mathrm{D}$-glucose, and ${ }^{68} \mathrm{Ga}$ G]EDTA in supratentorial tumors. $J$ Comput Assist Tomogr 1985; 9: 683-689.

320. Mosskin $M$, von Holst $H$, Bergström $M$ et al. Positron emission tomography with ${ }^{11} \mathrm{C}$-methionine and computed tomography of intracranial tumours compared with histopathologic examination of multiple biopsies. Acta Radiol 1987; 28: 673-681.

321. Kaschten B, Sadzot B, DelFiore G et al. Intérêt de la tomographie à émission de positons à l'aide de ${ }^{11} \mathrm{C}-m e ́ t h i o-$ nine dans l'étude des tumeurs cérébrales. Circ Metab Cerveau 1992; 9: 205.

322. Ogawa T, Shishido F, Kanno I et al. Cerebral glioma: evaluation with methionine PET. Radiology 1993; 186: 45-53.

323. Ogawa $\mathrm{T}$, Inugami A, Hatazawa $\mathrm{J}$ et al. Clinical positron emission tomography for brain tumors: comparison of fluorodeoxyglucose F18 and L-methyl-11 $\mathrm{C}$-methionine. AJNR 1996; 17: 345-353.

324. Kuwabara Y, Ichiya Y, Otsuka M et al. High [ ${ }^{18 F] F D G ~ u p-~}$ take in primary cerebral lymphoma: a PET study. $J$ Comput Assist Tomogr 1988; 12: 47-48.

325. Rosenfeld SS, Hoffman JM, Coleman RE et al. Studies of primary central nervous system lymphoma with fluorine-18fluorodeoxyglucose positron emission tomography. $J \mathrm{NuCl}$ Med 1992; 33: 532-536.

326. Di Chiro G, Hatzawa J, Katz DA et al. Glucose utilization by intracranial meningiomas as an index of tumor aggressivity and probability of recurrence: a PET study. Radiology 1987 ; 164: $521-526$.

327. Francavilla TL, Miletich RS, De Michele D et al. Positron emission tomography of pituitary macroadenomas: hormone production and effects of therapies. Neurosurgery 1991;28: $826-833$.

328. Griffeth LK, Rich KM, Dehdashti F et al. Brain metastases from non-central nervous system tumors: evaluation with PET. Radiology 1993; 186: 37-44.

329. Worthington C, Tyler JL, Villemure JG. Stereotaxic biopsy and positron emission tomography correlation of cerebral gliomas. Surg Neurol 1987; 27: 87-92.

330. Hanson MW, Glantz MJ., Hoffman JM et al. FDG-PET in the selection of brain lesions for biopsy. $J$ Comput Assist Tomogr 1991; 15: 796-801.

331. Levivier M, Goldman S, Bidaut LM. et al. Positron emission tomography-guided stereotactic brain biopsy. Neurosurgery 1992; 31: 792-797.

332. Levivier M, Goldman S, Pirotte B et al. Diagnostic yield of stereotactic brain biopsy guided by positron emission tomography with [18F]fluorodeoxyglucose. J Neurosurg 1995; 82: $445-452$.

333. Gwan Go K, Keuter EJW, Kamman RL et al. Contribution of magnetic resonance spectroscopic imaging and $\mathrm{L}-\left[1-{ }^{11} \mathrm{C}\right] \mathrm{ty}-$ rosine positron emission tomography to localization of cerebral gliomas for biopsy. Neurosurgery 1994; 4:1002.

334. Pirotte B, Goldman S, Bidaut LM et al. Use of positron emission tomography (PET) in stereotactic conditions for brain biopsy. Acta Neurochir (Wien) 1995; 134: 79-82.

335. Tyler JL, Diksic M, Villemure JG et al. Metabolic and hemodynamic evaluation of gliomas using positron emission tomography. J Nucl Med 1987; 28: 1123-1133.
336. Heiss WD, Heidel W, Herholtz K et al. Positron emission tomography of fluorine-18-deoxyglucose and image-guided phosphorus-31 magnetic resonance spectroscopy in brain tumors. $J$ Nucl Med 1990; 31: 302-310.

337. Schifter T, Hoffman JM, Hanson MW et al. Serial FDG-PET studies in the prediction of survival in patients with primary brain tumors. J Comput Assist Tomogr 1993; 17: 509-516.

338. Francavilla TL, Miletich RS, De Michele D et al. Positron emission tomography of pituitary macroadenomas: hormone production and effects of therapies. Neurosurgery 1991; 28 : 826-833.

339. Patronas NJ, Di Chiro GD, Kufta $\mathrm{C}$ et al. Prediction of survival in glioma patients by PET. $J$ Neurosurg 1986; 62: $816-822$

340. Di Chiro G, Brooks RA. PET quantitation: blessing and curse [editorial]. J Nucl Med 1988; 29: 1603-1604.

341. Kim CK, Alavi JB, Alavi A et al. New grading system of cerebral gliomas using positron emission tomography with $\mathrm{F}$ 18 fluorodeoxyglucose. J Neurooncol 1991; 10: 85-91.

342. Schmidt KC, Lucignagni G, Sokoloff L. Fluorine-18-fluorodeoxyglucose PET to determine regional cerebral glucose utilization: a re-examination. $J$ Nucl $\mathrm{Med} 1996$; 37: 394 399.

343. Fulham MJ, Melisi JW, Nishimiya $\mathbf{J}$ et al. Neuroimaging of juvenile pilocytic astrocytomas: an enigma. Radiology 1993; 189: 221-225.

344. Theodore WH, Di Chiro G, Margolin R et al. Barbiturates reduce human cerebral glucose metabolism. Neurology 1986; 36: 60-64.

345. Ishizu K, Nishizawa S, Yonekura Y et al. Effects of hyperglycemia on FDG uptake in human brain and glioma. $J \mathrm{NuCl}$ Med 1994; 35: 1104-1109.

346. Herholtz K, Pietrzyk U, Voges J et al. Correlation of glucose consumption and tumor cell density in astrocytomas. $J \mathrm{Neu}$ rosurg 1993; 79: 853-858.

347. Fulham MJ, Brunetti A, Aloj L et al. Decreased cerebral glucose metabolism in patients with brain tumors: an effect of corticosteroids. J Neurosurg 1995; 83: 657-664.

348. Patronas NJ, Di Chiro G, Smith BH et al. Depressed cerebellar glucose metabolism in supratentorial tumors. Brain Res 1984; 291: 93-101.

349. Lilja A, Bergström K, Hartvig P et al. Dynamic study of supratentorial gliomas with L-methyl- ${ }^{11} \mathrm{C}$-methionine and positron emission tomography. AJNR 1985; 6: 505-514.

350. Derlon JM, Bourdet C, Bustany P et al. $\left[{ }^{11} \mathrm{C}\right] \mathrm{L}-$ methionine uptake in gliomas. Neurosurgery 1989; 25: 720-728.

351. Sato K, Kameyama M, Ishiwata K et al. Dynamic study of methionine uptake in glioma using positron emission tomography. Eur J Nucl Med 1992; 19: 426-430.

352. Sadzot B, Kaschten B, Delfiore G et al. ${ }^{11} \mathrm{C}$-methionine uptake in brain tumors measured by PET: early clinical results. In: Mazoyer BM, Heiss WD, Comar D, eds. PET studies on amino acids metabolism and protein synthesis. Dordrecht: Kluwer Academic; 1993: 243-254.

353. Bergström M, Collins VP, Ehrin $E$ et al. Discrepancies in brain tumor extent as shown by computed tomography and positron emission tomography using $\left[{ }^{68} \mathrm{Ga}\right.$ ]EDTA, $\left[{ }^{11} \mathrm{C}\right] \mathrm{glu}-$ cose, and [ $\left.{ }^{11} \mathrm{C}\right]$ methionine. J Comput Assist Tomogr 1983; 7 : 1062-1066.

354. Kaschten B, Sadzot B, Stevenaert A. Evaluation of brain tumor metabolism by PET. I Neurooncol 1994; $21: 2$.

355. Borbely K, Fulham MJ, Brooks RA et al. PET-fluorodeoxyglucose of cranial and spinal neuromas. J Nucl Med 1992; 33: 1931-1934. 
356. Glantz MJ, Hoffman JM, Coleman RE et al. Identification of early recurrence of primary central nervous system tumors by F-18-fluorodeoxyglucose positron emission tomography. Ann Neurol 1991; 29: 347-355.

357. Ito M, Patronas NJ, Di Chiro G et al. Effect of moderate level X-radiation to brain on cerebral glucose utilization. $J$ Comput Assist Tomogr 1986; 10: 584-588.

358. Abe Y, Matsuzawa T, Fujiwara T et al. Assessment of radiotherapeutic effects on experimental tumors using ${ }^{18} \mathrm{~F}-2$-fluoro-2-deoxy)D-glucose. Eur J Nucl Med 1986; 12: 325328.

359. Kubota K, Matsuzawa T, Takahashi T et al. Rapid and sensitive response of carbon-11-L-methionine tumor uptake to irradiation. $J$ Nucl Med 1989; 30: 2012-2016.

360. Mineura K, Yasuda T, Kowada M et al. Positron emission tomographic evaluations in the diagnosis and therapy of multifocal glioblastoma. Pediatr Neurosci 1985-1986; 12: 208-212.

361. Ogawa T, Uemura K, Kanno I et al. Delayed radiation necrosis of brain evaluated by positron emission tomography. Tokohu J Exp Med 1988; 155: 247-260.

362. Rozental JM, Levine RS, Nickles RJ, Dobkin JA. Glucose uptake by gliomas after treatment. A positron emission tomographic study. Arch Neurol 1989; 46: 1302-1307.

363. Hölzer T, Herholtz K, Jeske J, Heiss WD. FDG-PET as a prognostic indicator in radiochemotherapy of glioblastoma. $J$ Comput Assist Tomogr 1993; 17: 681-687.

364. Holthoff VA, Herholtz K, Berthold F et al. In vivo metabolism of childhood posterior fossa tumors and primitive neuroectodermal tumors before and after treatment. Cancer 1993; 72: 1394-1403.

365. Patronas NJ, Di Chiro G, Brooks RA et al. Work in progress: $\left[{ }^{18} \mathrm{~F}\right]$ fluorodeoxyglucose and positron emission tomography in the evaluation of radiation necrosis of the brain. Radiology 1982;144: 885-889.
366. Di Chiro G, Oldfield E, Wright DC. et al. Cerebral necrosis after radiotherapy and/or intraarterial chemotherapy for brain tumors: PET and neuropathologic studies. AJNR 1987; 8: 1083-1091.

367. Doyle WK, Budinger TF, Valk PE et al. Differentiation of cerebral radiation necrosis from tumor recurrence by F-18FDG and Rb-82 positron emission tomography. $J$ Comput Assist Tomogr 1987; 11: 563-570.

368. Valk PE, Budinger TF, Levin VA et al. PET of malignant cerebral tumors after interstitial brachytherapy. Demonstration of metabolic activity and correlation with clinical outcome. $J$ Neurosurg 1988; 69: 830-838.

369. Ogawa T,. Kanno I, Shishido F et al. Clinical value of PET with ${ }^{18} \mathrm{~F}$-fluorodeoxyglucose and L-methyl- ${ }^{11} \mathrm{C}$-methionine for diagnosis of recurrent brain tumor and radiation injury. Acta Radiol 1991; 32: 197-202.

370. Ishikawa M, Kikuchi H, Miyatake S et al. Glucose consumption in recurrent gliomas. Neurosurgery 1993; 33: 28-33.

371. Janus TJ, Kim EE, Tilbury $R$ et al. Use of $\left[{ }^{18} \mathrm{~F}\right]$ fluorodeoxyglucose positron emission tomography in patients with primary malignant brain tumors. Ann Neurol 1993; 33: $540-548$.

372. Mogard J, Kihlström L, Ericson K et al. Recurrent tumor vs radiation effects after gamma knife radiosurgery of intracerebral metastases: diagnosis with PET-FDG. J Comput Assist Tomogr 1994; 18: 177-181.

373. Lilja A, Ludqvist $\mathrm{H}$, Olsson $\mathrm{Y}$ et al. Positron emission tomography and computed tomography in differential diagnosis between recurrent or residual glioma and treatment-induced brain lesions. Acta Radiol 1989; 30: 121-128.

374. Sawataishi J, Mineura K, Sasajima $T$ et al. Effects of radiotherapy determined by ${ }^{11} \mathrm{C}$-methyl-L-methionine positron emission tomography in patients with primary cerebral malignant lymphoma. Neuroradiology 1992; 34: 517-519. 